\title{
Akkumulation und Mittelklassen
}

\author{
Zur Diskussion über die Theorie der neuen Mittelkiassen
}

Norbert Kostede

\section{Einleitung}

Die folgenden Ausfuhungen haben im I. Teil den Begriff der Mittelklassen zum Gegenstand. Sie greifen die Kontroverse zwischen Gerhard Armanski und Joscha Schmierer auf (1), in der es un die Bestimmung der Mittelklassen und ihre Entwicklung in đer Klassenstruktur der bürgerlichen Gesellschaft ging. Armanski gelang es in dieser Kontroverse, Widersprüche der Mittelklassen.Theorie bei Schmierer und dessen obenfächliche strategische Schlußfolgerungen aufzudecken. Doch wird in der vorliegenden Arbeit kritisiert, daß Armanski die spezifische Relevanz des Begriffs der Mittelklassen verkennt und diesen Begriff als im Rahmen einer marxistischen Klassentheorie uberflüssig erscheinen läßst, wenn er die Mittelklassen-Konstruktion Schmierers in den allesumfassenden ,Oberflächenbegriff von Lohnarbeiterklasse" einbeziehen will. Indem wir im I. Teil des A ufsatzes den Begriff der Mittelklassen bei Marx und den klassentheoretischen Zusammenhang betrachten, in dem diese Kategorie bet ihm eingeführt wird, soll gezeigt werden, dak diesem Begriff in der Entwicklung einer materialistischen Klassentheorie durchaus Bedeutung zukommt. Vorweg sei gesagt, der Begriff der Mittelklassen hilft uns, zentrale Klassenstrukturen der bürgerlichen Gesellschaft zu benennen und dient als ein Ausgangspunkt in der Analyse wirklicher, historischer Klassenkämpfe.

De Herausbildung der herrschenden Klassenstrukturen muß aus dem spezifisch ökonomischen Prozeß dieser Gesellschaftsformation begriffen werden, aus dem Akkumulationsprozeß des Kapitals. Dies ist der Anspruch der materialistischen Klassentheorie. So werden wir im weiteren Verlauf dieses A ufsatzes die materiellen, ökonomischen Bedingungen verfolgen, denen das Wachstum der modernen Mittelklassen unterliegt. Welche Gesetzmäßigkeiten liegen diesem Wachstum zugrunde, wo liegen die Grenzen dieser Ausdehnung und wodurch werden sie gesetzt? Verweist der Begriff dieser Gesetzmäßigkeiten und Bestimmungen auf spezifische ,imperialistische oder, spätkapitalistische ${ }^{6}$ Bedingungen, wie von verschiedenen Autoren (z.B. Kuczinski, Mandel, Offe) behauptet wird? Oder haben wir es hier mit Prozessen zu tun, welche in ihrer Wirksamkeit der herrschenden Produktionsweise allgemein zukommen? - Im II. und III. Teil dieser Arbeit wird versucht, derartige Fragen zu beantworten, indem wir von den Bewegungen der produktiven Arbeiter-

1) 3. Schmierer: Die neuen Mittelklassen und das Proletariat, Neues Rotes forum (NRF) 4/71; G. Armanski: Zur Kritik der Theorie der neuen Mittelklasse, PROKLA 4/72: 3. Schmierer: Keine Zugeständnisse an den Revisionismus in der Klassenanalyse, NR: 6/72; Bericht des Klassenanalyseprojekts: Zur klassenanal a der Studenten, Eriangen 1972 
bevölkerung ausgehend die im Akkumulationsprozeß des Kapitals konstituierten Bestimmungen entwickeln, die uns das Wachstum der Mittelklassen begreifen lassen. Im Gegensatz zu den angeführten Autoren werden wir zu dem Schluß gelangen, daß die absolute und relative Ausdehnung der Mittelklassen das Klassengefüge der bürgerlichen Gesellschaft von Beginn an charakterisiert.

Wenn im ersten Teil dieses $A$ ufsatzes begründet wird, daß die Herausbildung der zentralen Klassenstrukturen, wie sie im Fortschritt der herrschenden Gesellschaftsformation immer deutlicher hervortreten, gewissermaßen als Reflex der inneren Widersprüche des Akkumulationsprozesses zur Darstellung gebracht werden muß, so unterscheidet sich dieser Ansatz in methodischer Hinsicht von vier bekannteren klassentheoretischen Konzeptionen:

Zum einen grenzt er sich von denjenigen Klassenanalysen $a b$, in denen unter dem Motto der „Klassenstrukturanalyse " letztlich die - je nach Klassen- und Schichtendefinitorik unterschiedliche - Interpretation ,sozialstatistischer Fakten" der Beschäftigungs-, Einkommens-, Vermögensstatistik etc. ins Zentrum der Analyse rückt (2), nicht selten mit dem - hier polemisch formulierten - Ergebnis, daß $80 \%$ und nicht $70 \%$ der Gesamtbevölkerung zur ,Lohnarbeiterklasse" zu zählen sind. Dort, wo der innere Motor der Klassengliederung unbegriffen bleibt, bleibt nichts, als der vorschnelle Griff zu den vielfältigen empirisch-statistischen Reflexen der Klassenentwicklung. - Zum anderen unterscheidet sich die vorliegende Arbeit von einer Konzeption, in der man ,,auf jegliche Floskel eines erstarrten Kapitalbegriffs verzichtend" sich in der isolierten Betrachtung des industriellen Arbeitsprozesses verliert (3). In diesem Ansatz versucht man, die herrschenden Klassenstrukturen ausgehend von den Antagonismen und Herrrschaftsformen der wirklichen Arbeitsprozesse zu begreifen: der sozialen Besonderung der intellektuellen Arbeitsfunktionen, dem Widerspruch von Kopf- und Handarbeit, der hierarchischen Befehlsstruktur kapitalistischer Betriebe oder bürokratischer Apparate etc. Auch wenn Momente und Widerspruchsformen, die in diesen beiden skizzierten Konzeptionen analysiert werden, eine gewichtige Bedeutung im Konstitutionsprozeß der wirklichen Klassenkämpfe erlangen, muß bestritten werden, daß diese Momente zum Ausgangspunkt oder Zentrum einer materialistischen Klassentheorie erhoben werden können.

Während auf diese beiden Richtungen im folgenden nicht nochmals eingegangen wird, haben wir gegen Schluß dieser Arbeit eine Position aufzugreifen, in der die okonomische Bestinmtheit der modernen Klassenstrukturen verneint wird. In der Tat ist die Klassenstruktur der bürgerlichen Gesellschaft kein bloßer Reflex der Bewegungen des Werts in der Form kapitalistischer Akkumulation, vielmehr gehen politisch-staatliche oder ideologische Notwendigkeiten und Prozesse bestimmend

2) Siche z. B. den Bericht über die Tagung des IMFS, Mai 1973, zu Fragen der Klassenstruktur und des Klassenbewulstseins in der BRD; in: SOZIALISTISCHE POLITIK 24/1973, S. $51 \mathrm{ff}$. Die Ergebnissc und methodischen Ausführungen auf dieser Tagung schliefsen im wesentlichen an die früheren Arbeiten von K. H. Tjaden, H. Jung, L. Peter u. a. an. Diese Tendenz erscheint am ausgeprägtesten in den Ausläufern der linken französischen Industriesoziologic bei A. Gorz, S. Mallet u. a. Doch auch die Autoren der PROLETARISCHEN IRONT Heft 10 , die hier zitiert wurden, bleiben in ihrer Konstruktion des „Typus des Massenarbeiters" im Grunde einer isolierten Betrachtung des Arbeitsprozesses verhaftet: Arbeiterkampf in Deutschland, München 1973. 
und vermittelnd in die Herausbildung der Klassenstruktur ein und gewähren diese! eine bestimmte Eigenbewegung gegenüber den Bewegungen des Akkumulationsprozesses. Doch wird zu zeigen sein. wie dieses Moment der Eigenbewegung im Rahmen der politischen Krisentheorie dazu herhalten muß, die sich in letzter Instanz durchsetzende ökonomische Bestimmtheit der herrschenden Klassenstrukturen zu bestreiten.

Begreift man die Klassengliederung, wie sie die bürgerliche Gesellschaft charakterisiert, als Ausdruck kapitalistischer Akkumulation, so ergibt sich ebenso eine methodische Differenz zu den Arbeiten des Projekts Klassenanalyse. Zu Recht weisen die Autoren dieses Projekts auf die Bedeutung hin, die den spezifischen Formbestimmungen menschlicher Arbeit im Rahmen einer marxistischen Klassentheorie zukommt (4). Sie untersuchen die Formen der produktiven, unproduktiven und kommerziellen Arbeit auf die unterschiedlichen Brücken und Barrieren sich stufenförmig entwickelnden Klassenbewußtseins, fragen nach denjenigen Momenten, mittels welcher and gegen welche reales Bewußtsein über gesellschaftliche Verhältnisse herausgebildet wird und über welche es allererst aufzuschlüsseln ist. Doch werden wir am Ende dieses Aufsatzes zu zeigen haben, dak die Frage nach den zentralen Klassenstrukluren sich nicht im bloßen Nachvollzug der ökonomischen Formbestimmungen des gesellschaftlichen Reproduktionsprozesses und in der Entschlüsselung der Genese verkehrten Bewußtseins erschöpfen kann, sondern daß es gilt, den Prozeß $\beta$ der Klassengliederung auf seiner Basis, im Akkumulationsprozel des Kapitals zu entwickeln.

Nach dieser skizzenhaften Abgrenzung von kontroversen klassentheoretischen Ansätzen gehen wir dazu über, den eingangs begründeten Weg der Darstellung einzuschlagen.

\section{Teil}

Armanskis Kritik der Mittelklassen-Theorie - Zum Begriff der classe moyenne bei Marx

Für die Rekonstruktion einer materialistischen Klassentheorie geht es zunächst ganz ,orthodox" darum, den sich nicht gerade in offenkundiger Stringenz und Eindeutigkeit durch sein gesamtes Werk hindurchziehenden klassentheoretischen A nsatz Marxens zu gewinnen. Beließe man es bei einer Aufzählung einzelner markanter Formulierungen, wo mal von Bourgeoisie-Proletariat, mal von Bourgeoisie-MittelklassenProletariat, mal von Lohnarbeitern-Kapitalisten-Grundeigentümern etc. als den

4) Siche z. B. die Aufsätze in der SOZIALISTISCHEN POLITIK 6-8 über die Bedeutung der Kategorien produktive und unproduktive Arbeit. Ebenso den resümierenden Aufsatz des Projekts Klassenanalyse: Klassenbewndstsein und Partei, West-Berlin 1972 oder die neuere Veröfentlichung: Materialion zur Klassenstruktur der BRD, West-Berlin 1973. -Doch auch die A utoren des KOMMUNIST 4/5: Einschatzung des westdeut schen I naperialismus ..., West-Berin 1971 wiesen beizeiten auf die Bedcutung dieser Fategorien für eine marxistische Klassenanalyse hin. 
spezifischen, die kapitalistische Produktionsweise kennzeichnenden Klassen die Rede ist, so würde sich ohne die Kenntnis der jeweiligen theoriegeschichtlichen Hinter. gründe und darstellungslogischen Implikationen in der Tat der Eindruck bloker Differenzen und Widersprüche einstellen. Dies bedeutet, daß wir nicht bei der Konstatierung von Differenzen $2 w$ ischen Passagen fruherer oder später Schriften oder bei der Absolutiorung einer oder weniger isohert betrachteter warxscher Ausfuhrungen stehenbleiben können. Vielmehr kommi es darauf an den Marxschen Materialismus, wie er allererst in der Kritik der politischen Ökonomie seinen früheren, mehr programmatischen Charakter ablegt (1), auch in klassentheoretischer Hinsicht als gewordenen zu begreifen. Weder konnte die materialistische Theorie über Nacht die überkommenen Positionen der klassischen politischen Ökonomie von sich abstreifen (so in der Herausarbeitung der Kategorie des Mehrwerts, der produktiven Arbeit etc.), noch konnte sie andererseits, obwohl sie die allgerneinen Formen darsiellen will, worin sich die historische Bewegung des Kapitals und die Geschchte der Klassenkämpfe vollzieht, natirlich nicht unbelecki von denjenigen historischen Erscheinungen der Marxschen Epoche bleiben, denen in der Entwicklung der bürgerlichen Gesellschaft keine Perspektive zukommt. (So hat Marx $z$. s.s $_{\text {, wenn er auf }}$ Typen unproduktiver Arbeit zu sprechen kommt, häufig die ,dienenden Klassen" im Auge, die heute aber nur marginale Bedeutung haben.) Erst und letztlich im Prozeß der Kritik der politischen Ökonomie erlangt Marx den Schlissel fur die Arıalyse der inneren Zusammenhänge der Klassenbewegungen und Klassenstrukturen kapitalistischer Produktionsweise und kann zu konsistenten Aussagen uber deren Entwicklungstendenzen kommen. Und allein her können wir einsetzeni und fragen, ob seine Aussagen und Kategorien uns die Klassenstrukturen der fortgeschrittenen, nachmarxschen Gesellschaft begreifen lassen - oder nicht (3).

Dies vorausgesetzt, so dürfte unumstritten sein, dak der Begriff der Lohnarbeit bei Mard letztlich zwei vermittelte Aspek te umiafot:

a) Einmal die produktive Arbeit im besonderen, oder, wie Marx es in einer Stelle in den "Theorien über den Mehrwert" formuliert, die "Lohnarbeit im wissenschaftlichen Sinn", wo also mittels der Bestimmung dieser Form das Herrschafts-und Knechtschaftsverhältnis der burgerlichen Gesellschaft alleverst als historisches, $d . h$. spezifisch-formbestimmtes Produkionsverhältnis begreifbar wird (4), wo das Begreifen dieser Form zum "Springpunkt" der politischen Ökonomie wird und erst die Darstellung der herrschenden Antagonismen in ihren abzuleitenden Fomen möglich macht:

Kommt etwa die Fragt auf den antagonistischen Charakter der kapitalistischen Eigentumsverhältnisse, so hat uns nicht der bloße Besitz oder Nichtbesizz an kapita-

1) dazu H. Reichelt: Die naterialistische Geschichtsauffassung im Marxschen Fruhwerk, in: Zur logischen Striktur des Kapitalbegriffs bei Karl Marx, Frankfurt 1970.

2) entfällt

3) Wie etwa C. Offe bchauptet, demzufolge auch spezifische ,spätkapitalistische' Klassenund Schichtenbewegungen ,aus der Warenform herausfallen" und zu ihrer Erklärung den Begriff ,nichtkapitalistischer Formelemente" erforderten: Strukturprobleme des kapitalistischen Staates, Frankfurt 1972; wir werden sehen.

4) dazu MEW Bd. 25, S. 799 
listischem Eigentum zu interessieren, wie in der gängigen Handhabung der Marxschen Eigentumskategorie zumeist unterstellt wird (5), sondern hier in teressiert das ,negierte Eigentum", von mir selbst in der Form des Werts geschaffen und mir dennoch nicht (ge)hörig, das den im Produktionsprozefs des Kapitals konstituierten Antagonismus von Lohnarbeit und Kapital auch in der Form eines personifizierten Eigentums- und Aneignungsverhältnisses zum A usdruck bringt (6).

b) Zum anderen umfaist der Begriff der Lohnarbeit das, was Gerhard Armanski als ,Oberflächenbegriff von Lohnarbeiterklasse" bezeichnet hat; auf dem Weg zu dieser Ebene zeigt Marx, wie die Verallgemeinerung der Arbeit als Lohnarbeit notwendig mehr und mehr Bereiche einbeziehen muk, in denen menschliche Arbeit nicht als mehrwertproduzierende Arbeit fungiert, vielmehr als Zirkulationsarbeit Formwandlungsprozesse des Kapitals, andererseits als unproduktive Arbeit private Dienstleistungen, öffentlich-allgemeine Rahmenbedingungen der Produktion etc. erfüllen hillt.

Ohne hier die Vermittlungen beider Gesichtspunkte auszubreiten, ohne leugnen zu wollen, daß beide Aspekte in der Analyse der Widersprüche realer Klassenkämpre von jeweils spezifischer Bedeutung sind, so lautet doch die Frage nun, welcher dieser beiden Aspekte im Begriff der Lohnarbeit, und warum dieser und nicht der andere, als begrifticher Ausgangspunkt in der Bestimmung der revolutionären Klasse für Marx und für uns zu gelten hat. Mehr als begrifflicher Ausgangspunkt könnte dieser oder jener Aspekt ja nicht sein - Armanski zeigt ja treffend, wie bei Schmierer die Differenz von Begriff und Erscheinung, von klassentheoretischem Ansarz und realer Klassenanalyse unterschlagen wird, wie seine Position darum in widersprüchlichen Strategemen münden muß (7). Wird diese Differenz nicht reflektiert, wird bar jeglicher kategorialen Analyse realer und jeweils historisch-spezifischer Klassenverhältnisse und Klassenkampfformen die Bestimmung sozialistischer Strategie und Taktik einzig auf dem Boden einer - zudem noch oberflächlichen - Interpretation der Marxschen Klassentheorie versucht, so bleibt -- je nach Klassendefinitorik - nichts als die Auswahl zwischen zwei Sackgassen, die Auswahl zwischen einer ,Bündnis"ontologie oder zum anderen einer ,Vereinheitlichungs"ontologie als heiligstem Mittel und überhistorischem Prinzip jeglicher Arbeiterpolitik. Wird diese Differenz nicht reflektiert, kommt es halt zu jenen Kindereien, wo die einen ob der relativen Abnahme der produktiven Klasse und der damit ,immer schwierigeren Revolution" das große Zähneklappern haben (Nicolaus (8)), wo die anderen ob der ,70-90\%igen Lohnarbeiterklasse diesem Riesen nur noch das nötige Klassenbewußtsein ,hineinzutragen ' haben, bis dieser dann tief Luft holend seine Fesseln sprengt. - Nun, welcher der beiden Aspekte im

5) Hier mag ein Verweis auf M. Mauke: Die Klassentheore von Marx und Engels, Frankfurt 1970 , S. 7 ff./165 -- oder auf H. Steiner: Soziale Strukturveränderungen im modernen Kapitalismus, Bcrlin 1967, insb. S. 100/110 t. genügen.

6) Vgl. dazu etwa K. Marx: Grundrisse der Kritik der politischen Ökonomie, FVA, Frankfurt 1969, S. $373 \mathrm{f}$.

7) Siehe dazu auch das Vorwort zur 2. Auflage des Berichts des Klassenanlyseprojekts: Zur Klassenanalyse ..., a. a. O.

8) Siehe M. Nicolats: Zur Klassentheoric bei Marx, Berlin 1970. 
Begriff der Lohnarbeit bei Marx, so fragen wir nochmals, verhilft uns zu einer stringenten Fassung seines klassentheoretischen Ansatzes und zu einem begrifflichen Ausgangspunkt in der Bestimmung der revolutionären Klasse der bürgerlichen Gesellschaft, wobei mit dem meines Erachtens zentralen Mangel des Aufsatzes Gerhard Armanskis zu beginnen sein wird.

Marx sagt an der bekannten Stelle in den ,T Theorien uber den Mehrwert"“, daßs, da die Masse der classe moyenne wachse, „das Proletariat einen verhälinismäßig immer kleineren Teil der Gesamtpopulation bildet (wenn es auch absolut wächst). Dies ist in der Tat deг Gang der Bourgeoisgesellschaft" (9). Dem sei so mitnichten, sagt Gerhard Armanski, wenn man nur Marxens eigene Bestimmung der classe moyenne heranziehe:

„Lnter Mittelklassen falst Marx durchgehend die ,dienenden Klassen ", persönliche Dienstleistende, ideologische Stände, Nichtarbeitsfahige und Rentiers, kurz all diejenigen, die dem persönlichen Konsum und/oder der politischen Herrsehaft der Kapitalistenklasse dienen, zu jung oder 24 at zum Arbeiten sind oder an industricll produzierten Mehrwert zehren, keineswegs aber die Zirkulationsarbeiter und Teile der Arbeiter und Angestellten beim Staat (z. B. Lehrer $)^{\prime \prime}(10)$.

Insofern aber der Marxsche Begriff der Mittelklassen durchgehend diese ,,dienenden Klassen" meine, so dürften die empirirschen Befunde des gegenwärtigen Forschungsstandes reichen, um zu zeigen, daß der von Marx behauptete „Gang der Bourgeoisgesellschaft" nicht eingetroffen sei, da -- was unbestreitbar ist - die ,dienenden Klassen" im Fortschritt der burgerlichen Gesellschaft eine immer unbedeutendere Rolle spielen (11). Kurzum; Gerhard A rmanski gemäß kann von einer relativen Abnahme des Proletariats und damit von einer relativen Zunahme der Mittelklassen als einer die Klassenstruktur der Gesantbevolkerung kennzeichnenden Tendenz nicht die Rede sein.

Nun hat er mit der Behauptung, Marx habe keinesfalls , die Zirkulationsarbeiter und Teile der Arbeiter und Angestellten beim Staat (z. B. Lehrer) " mit dem Begriff der Mittelklassen fassen wollen, was erstere angeht, also die kommerziellen Arbeiter, hier zum Teil Recht, da Marx in einigen Passagen der ,Theorien über den Mehrwert" noch die Zirkulationsarbeit als produktive Arbeit betrachtet hat (12), was dann später insbesondere im 2. Band des „Kapital" begrifflich strenger voneinander geschieden werden kann. Was die letzteren angeht, so würde bereits ein oberflächliches Nachschlagen ausreichen, um zu beweisen, daß diese Bereiche für Marx unter die Kategorie der classe moyenne fallen: alle Träger von unproduktiven Funktionen beim Staat (seien sie zunächst hauptsächlich Beamte, später mehr und mehr Angestellte oder gar Arbeiter) und natürlich auch „Gelehrte und Schulmeister“

10) Armanski: a. a. O., S. 51

11) ders.: a. a. O., S. 52: auf den Aspekt der unproduktiven Konsumtion, der in diesem Zusammenhang immer hereinspielt und ebenfalls zu diskutieren wäre, werden wir der diffizilen Ableitung halber später cingehen müssen. Z. B. MEW Bd. 26.1, S. 190 
gehen bei ihm in die classe moyenne ein (13), auch wenn Marx, um diesen Begriff zu beinhalten, häufig auf die einzig seiner Epoche eigentümliche Erscheinung der immensen Ausdehnung der ,dienenden Klassen“ und der beschleunigten Vermehrung der ,modernen Haussklaven“ zurückgreift (14). Wird also A rmanski der Marxschen Kategorie der Mittelklassen schon dadurch nicht gerecht, daß er die classe moyenne und die "dienenden Klassen " nahezu identifiziert und so diesen Begriff weitaus enger bestimmt als es bei Marx der Fall ist, so kann ihm andererseits nicht die Kritik erspart bleiben, mit dem Verweis auf die Vergänglichkeit einer historisch-besonderen Erscheinungsform unproduktiver Arbeit, nämlich der relativen Expansion der ,dienenden Klassen“, dasjenige zu verwerfen, was Marx als charakteristische und allgemeine Tendenz der Bewegung der modernen Klassen zum Ausdruck bringt. Es mag dogmatisch klingen, ist es aber nicht, wenn hier darauf insistiert wird, daß Marx sich nicht irrt, wenn er von der tendenziell relativen Abnahme des Proletariats an der Gesamtbevölkerung redet, vielmehr formuliert Marx an diesen Stellen (15), was sich aus den grundlegenden Gesetzmäßigkeiten der Entfaltung kapitalistischer Akkumulation als abzuleitende klassentheoretische Konsequenz ergibt:

Wir haben es hier nicht mit der isolierenden Interpretation einer oder weniger verquerter Formulierungen oder einer einzig der Marxschen Epoche eigenen Bestimmung zu tun, vielmehr sind wir beim eigentlichen Kern, der Frage nach dem klassentheoretischen Ansatz Marxens angelangt. Denn vergewissern wir uns des Gangs der Darstellung der zentralen Momente und Gesetzmäß3igkeiten kapitalistischer Akkumulation im "Kapital“, wie sie sich in den letztlich durch das anumerische Wachstum von Produktivkraft und Mehrarbeitszeit verursachten, dann über jeweils reellere Momente generierten Bewegungen der durchschnittlichen Profitrate zuspitzen und die Prozesse der empirischen Konkurrenz durchdringen, so finden wir im Nachvollzug dieses Darstellungsgangs eine Fülle von Bestimmungen darüber, wie die absoluten und relativen Wachstumsbewegungen der Klasse der produktiven Arbeiter als polarisches Produkt im Verlauf der Akkumulation von Kapital erscheinen (16). Und einzig und allein im Nachvollzug der inneren Widersprüchlichkeiten des Akkumulationsprozesses konnen wir begreifen, warum Marx angesichts der sich entfaltenden und sich ausbreitenden industriellen Produktivkräfte vom Proletariat als einem relativ immer kleineren Teil der Gesamtbevölkerung der bürgerlichen Gesellschaft reden kann, weshalb diese Klasse im historischen Prozeß der Akkumulation

13) Z. B. MEW Bd. 26.1, S. $130 / 135 / 146$ f./189 f./254/381; MEW Bd. 26.2, S. 469; MEW Bd. 26.3, S. 44 tif.

14) Dazu MEW Bd. 23, S. 469 f.; zentrale Ursachen für dỉc Umkehr dieser Entwicklung sind in der Technisierung der individuellen Reproduktionsprozesse, in der Kapitalisicrung der Dienstleisrungsbereiche, der relativen Abnahme der Bourgcoisklasse und der marginalen Entwicklung der Grundeigentümerklasse zu suchen, was uns jedoch nicht näher interessicren muls.

15) Insbesondere auch MEW Bd, 26.1, S. 189/199.

16) Siehe dazu insb. die Abschnitte über die Produktion des relat. Mehrwerts und über den Akkumulationsprozeds des Kapitals im 1. Band sowie den Abschnitt über das (iescrz des tendenz. Fals der Protitrate im 3. Band des ,Kapital"; wir werden auf diesen Aspekt im II. Teil des A ufsatzes zurückkommen. 
absolut an Umfang gewinnt und durch eben diesen Prozeis an relativem Umfang verlieren muß: die Herausbildung der zentralen Klassenstrukturen der bürgerlichen Gesellschaft muis aus den inneren Widersprüchen des kapitalistischen Akkumulationsprozesses entwickelt werden.

Sehen wir von den berechtigten Momenten der Kritik an Joscha Schmierers und Martin Nicolaus' Auffassungen ab und rekapitulieren wir kurz einigo zentrale Argumente, die sich allgemein gegen den Begriff der Mittelklassen und gegen den Begriff der produktiven Arbeit als Ausgangspunkt in der Gewinnung der revolutionären Klasse richten:

Wenn Gerhard Armanski schreibt, es sei ,nicht cinzusehen, daf die kommerziellen Arbeiter in der Zirkulation, die ja notwendiges Moment der Reproduktion des Kapitals ist, zu den Mittelklassen zählen sollen "(17), wenn er gegen die --von Schmierer oberflächlich-moralisierend gewandte - These, derzufolge unproduktive Mittelklassen ihre Revenuen auch auf Kosten der produktiven Klasse ausdehnen können (18), ausführt, daß dabei völlig verlorengehe, ,daß die überwältigende Mehrheit der Lohnabhängigen gesellschaftlich notwendige Arbeit verrichtet ${ }^{t 5}$ (19), so kann dies natürlich kein Kriterium für den Begriff der Arbeiterklasse, ja nicht einmal ein Kriterium für den „Oberflächenbegriff der Lohnarbeiterklasse“ sein. Denn wer verrichtet schon keine notwendige A rbeit für diese Gesellschaft (Polizei- und Militärapparate; alle ideologischen Stände; Abteilungen der Bourgeoisie, insofern sie Zirkulationsarbeiten ausrichten etc.), alle Klassen sind als in den Gesamtreproduktionsprozeß des Kapitals einbezogen notwendig, lassen wir rudimentäre überkommene Produktionsweisen einmal außerhalb der Betrachtung. Formuliert man dieses Argument derart, daß man anführy (20), daß nicht alle in der Produktionsprozeß, sondern der Reproduktionsprozeß des gesellschaftlichen Gesamtkapitals erfafit werden müsse, so wären nicht allein alle Zirkulationsarbeiter (also Reproduktionsprozeßs im engeren Sinn als Zirkulationsprozeß begriffen), sondern dann wären konsequenterweise alle Klassen und Schichten dieser Gesellschaft, die Zirkulationsbedingungen, allgemeine Rahmenbedingungen der Produktion, private Dienstleistungen etc. erfüllen helfen, zur Arbeiterklasse zu zählen, gleichgültig ob sie dies in der Form der Lohnarbeit ausrichten oder nicht: Kurz, die Notwendigkeit der Arbeit taugt nicht für den Begriff der Klassenstrukturen bürgerlicher Gesellschaft.

Man führt an, daß ein klassentheoretischer Ansatz, der die produktive Arbeit als Ausgangspunkt des Bestimmens der revolutionären Arbeiterklasse begreift, sich allein auf das ,individuelle Kapital", auf das „Einzelkapital“" beziehe:

„Die A useinanderreifung des kapitalistischen Produktions- und Reproduktionsprozesses durch die Unterscheidung von Lohnarbeit und "Lohnarbeit im wissenschaftlichen Simn" hypostasiert und isoliert die verschiedenen Sphären der gesellschaftlichen Arbeit voneinander. Das, innere Band" der kapitalistischen Produktionsweise, die Bewegung des sich verwertenden Werts, wird

17) Armanski: a. a. O., S. 57

18) Wir werden diesen Aspekt in Ill. Teil zu bchandeln haben.

19) Armanski: a. a. O., S. 59; von mir hervorgehoben.

20) ders.: a.a. O., S. $57 \mathrm{f}$. 
zerschnitten ${ }^{6 *}(21)$.

Die widersprüchliche Konstitution der Lohnarbeiterklasse an der Obertlache der bügerlichen Eesellschaft" worde willkürdich auscinandergerissen (22).

Nun wurde bereits darauf hingewiesen, daß die notwendige Verallgemeinerung der Form der Lohnarbeit über den kapitalistischen Produktionsprozeß hinaus für die Analyse der Widerspriiche der realen Klassenkämpfe von eminenter Bedeutung ist und dieser Aspekt im Begriff der Lohnarbeit uns einen kategorialen Schlüssel für das Aufdecken und die Darsiellung der realen Zwänge und Herschaftsformen gibt, denen zunehmend auch diese Bevölkerungsteile der bürgerlichen Gesellschaft im zyklischen Gang der Akkumulation und in der arbeitsteiligen Verödung und Entleerung der wirklichen kommerziellen und unproduktiven Arbeitsprozesse ausgeliefert sind. Dennoch geht man in der Behauptung fehl, eine klassentheoretische Konzep. tion, wie sie hier zu rekonstruieren versucht wird, nehme den. Standpunkt des „,individuellen Kapitals" zum Ansatz. Wie man in dieser Behauptung einerseits eine oberflächliche Identität von ,Einzelkapital“ und produktivem Kapital impliziert, mit dem wir es her in Wirklichkeit zu tun haben, so wird zum anderen der weitere Gang der Ausführungen noch ersichtlich werden lassen, daß die absoluten und relativen Bewegungen der produktiven Klasse, wie Marx sie in den ,Theorien über den Mehrwert" konstatiert und wie sie sich im ,Kapital" über ihre abgeleiteten Momente darstellen, allein unter Einbezug der Ebene der Gesamtbetrachtung der Kapitalbewegung und der verschiedenen Sphären gesellschaftlicher Arbeit bestimmbar werden.

In einer brieflichen Kontroverse brachte Martin Reimann u. a. folgenden Einwand gegen das Begriffspaar Proletariat-Mittelklassen vor: Die Verwendung dieser Kategorien erlaube nicht, die veräußerlichten Formen an der Oberfläche bürgerlicher Gesellschaft zu dechiffrieren:

,Das Begrifíspaar Proletariat-Mittelklassen drückt nicht aus das Verhältnis

a) von Zirkulations- zu produktiven Arbeitern,

b) von produktiven und Zirkulationsarbeitern zu "Dienstleistenden " und

c) die Konsequenzen, die sich ergeben aus der alien A rbeiten gemeinsamen lorm der Lohnarbeit.

All das gehört zur Marxsehen Klassentheorie. Der Begriff der Arbeiterklasse entwickelt und veräuberlicht sich im Gang der Marxschen Theorie. Wir müssen gerade die veräufberlichten Oberflächenphänomene erklären, also ,schritrweise entwickehn, und erst in diesem Zusammenhang ergibt sich die spezifische, relative Bedeutung des Begriffspaars Proletariat-Mittelklassen."

Es kann überhaupt nicht ignoriert werden, daß der Begriff der Mittelklassen des ofteren in einer Weise verwandt wird, die die jeweils spezifischen Verhältnisse dieser drei sich im Verlauf der kapitalistischen Produktionsweise entfaltenden Arbeitsformen verschüttet. So etwa Karl-Heinz Roth:

„Im gegenwärtigen Kapitalismus gibt es drei spezifische Hauptklassen, die sich in ihrer Stellung zum Gesamtreproduktionsprozeis des Kapitals elementar unterscheiden: die Arbeiterklasse, die

21) Armanskj: a. a. O., S. 55

22) Klassenanalyseprojekt: a. a.O., S. 13 
Mittelklasse und die herrschende Klasse... Sie sind ... wesentlich konstituiert durch ihr Verhältnis zur Mehrwertproduktion, indem sie den Mehrwert entweder schaffen (Arbeiterklasse), sich aneignen (herrschende Klasse) oder sich durch unproduktive Arbeit gegen einen Teil des Mehrwerts, die Revenue, austauschen (Mittelkiasse)" (23).

Ein derartiges Konstrukt erweckt den Eindruck, als bildeten die modernen Mittelklassen ein einheitliches Ganzes im Klassengefüge der bürgerlichen Gesellschaft, eben: die Mittelklasse. Hier werden in der Tat die letztlich in der jeweils spezifisch-unterschiedlichen ökonomischen Formbestimmtheit menschlicher Arbeit begründeten Klassenunterschiede verwischt. Klassenunterschiede, wie sie in den wirklichen Klassenverhältnissen und historischen Klassenkämpfen auf vielfältige Weise zum Ausdruck kommen: sei es in der unterschiedlichen Art und dem unterschiedlichen Umfang, in dem diese jeweiligen Klassen der Herrschaft des zyklischen Verwertungsprozesses unterworfen sind, sei es in der Unterschiedlichkeit der konkreten Funktionen ihrer Arbeit, in den notwendig unterschiedlichen politischen und ideoIogischen Artikulationsformen dieser Klassen, sei es in jeweils klassenspezifischen Sozialisationsprozessen etc. Selbst die eingeschränk te Fragestellung der folgenden Teile dieser Arbeit wird erkennen lassen, daß die Konstruktion einer einheitlichen Mittelklasse den jeweils spezifischen Verhältnissen im Gesamtreproduktionsprozeß des Kapitals nicht gerecht werden kann. -- Der Begriff der Mittelklassen muß also nicht zwangsläufig die spezifischen Verhältnisse produktiver, kommerzieller und unproduktiver Arbeiter verschütten, ebenso wie er es uns beläßt, die in der gemeinsamen Form der Lohnarbeit begründeten einheitlich erfahrbaren Widersprüche im gemeinsamen Kampf der Lohnarbeiter um die Erhaltung der menschlichen Arbeitskraft, der Sicherung, Verteidigung oder Erweiterung der jeweiligen Revenuen etc. aufzuspüren.

Um auf die oben aufgeworfene Frage zurückzukommen, welcher der beiden Aspekte im Begriff der Lohnarbeit bei Marx als Ausgangspunkt in der Bestimmung der revolutionären Klasse zu ergreifen ist, so ist, was Gerhard Amanski angeht, die Sache klar: er will vom zweiten Aspekt ausgehend fragen, welche "Abteilungen“" der Lohnabhängigen zur Arbeiterklasse zu rechnen sind und welche nicht (24), oder, wie im Bericht des Klassenanalyseprojek ts gesagt wird, welche Teile der Lohnarbeiter zu "neutralisieren", welche zu ,isolieren", welche zu „vereinheitlichen" sind (25).

Für einen Ansatz, der nicht den ,Oberflächenbegriff“", sondern die historisch-spezifische Form der Lohnarbeit als produktive, mehrwertproduzierende Arbeit als klassentheoretischen Ausgangspunkt begreift, stelit sich der Gang anders dar: ausgehend von und auf der Basis der Marxschen Darstellung der Bewegungen und Strukturen der Klassen der bürgerlichen Gesellschaft, gewonnen im Nachvoll-

23) Davon, daks ein grober Teil der Mittelklassen sich nicht allein gegen Mehrwert, sondern auch gegen den Lohn der produktiven Arbeit tauscht, wollen wir hier absehen. Fbenso davon, dals die Zirkulationsarbeit umstandslos unter die unproduktive Arbeit subsumiert wird. K. H. Roth: Intelligenzproblem-Scheinproblem, in: Diskus, Frankfurt 1971, S. 7

24) Armanski, a. a. O., S. 56

25) Klassenanalyseprojekt: a. a. O., S. 18 
zug der Bewegungen kapitalistischer Akkumulation, will diese Konzeption in der Analyse realer Klassenkämpfe hinterfragen, welche Bereiche und Schichten der produktiven Klasse und der modernen Mittelklassen den zugespitzten und vielfältigen Torturen der kapitalistischen Verwertungszwänge unterliegend und in der Hetze und bornierten Arbeitsteiligkeit wirklicher Arbeitsprozesse geknechtet zum immer allein realen und historischen revolutionären Subjekt zusammengeschweiß werden. Erst die konkrete Geschichte der Klassenkämpfe form t das revolutionäre Subjekt zu einer wirklichen Einheit von okonomischen, politischen und ideologischen Beziehungen und Zusammenhängen. Erst unter Einbezug dieser Ebene wird die Frage nach Strategie und Taktik beantwortbar, werden diese Antworten sich erweisen als revolutionär oder revisionistisch. Erst hier ordnet das Proletariat als wirkliches Subjekt seine eigenen Reihen und fragt andererseits nach Klassen und Schichten, die, obwohl nicht in allesumfassend-antagonistischem Widerspruch zum Kapital stehend, in mannigfachen manifesten und sublimen Formen unter seiner erbarmungslosen $\mathrm{Na}$ turgesetzlichkeit und seinem blinden ,Fortschrit!" leiden und im Voranschreiten der Klassenkämpfe auf die Seite des Broletariats gezogen werden können.

Unter diesen Voraussetzungen muk am Begriff der Mittelklassen und am Begriff des Proletariats als der spezifisch-formbestimmten Knechtschaft der Kapitalistischen Gesellschaft und dem Verständnis der Form herrschender Klassenstrukturen als Ausdruck kapitalistischer Akkumulation festgehalten werden. Wer die Mittelklassentheorie Schmierers als oberflächliches und widersprüchliches Strategem aufdeckt, braucht nicht diese Begriffe als Ausgangspunkte der Analyse realer Klassenkämpfe uber Bord werfen.

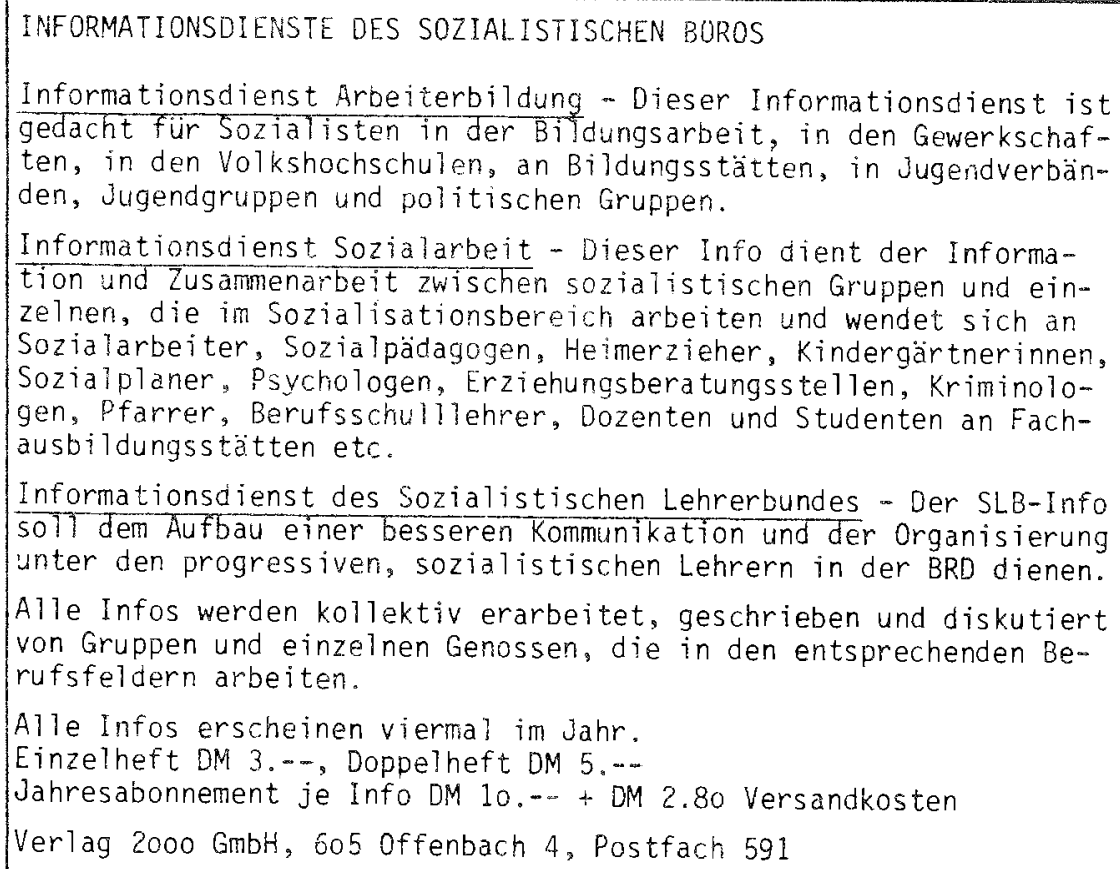



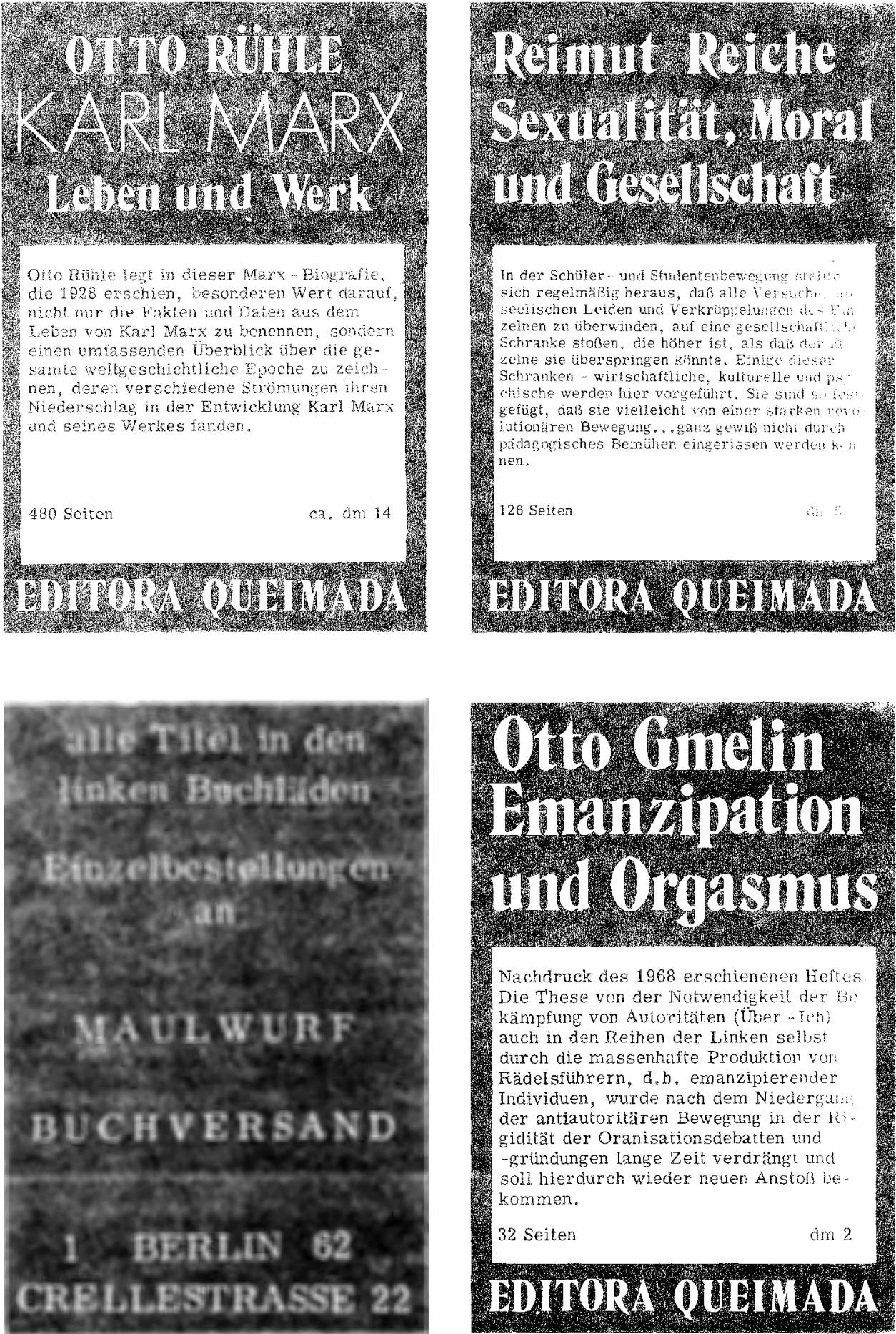
1. Tell

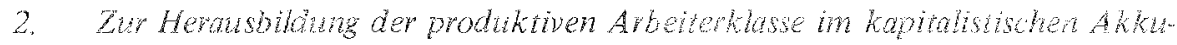
mulationsprozes

Un die Bewegugen der modernen Miteiklassen m kabahstischen Akh whia tionsprozeß nachzuvolzichen, müssen zunächst in groben Zigen diejengen Momen. te rekapituliert werden, walche die Entwicklung der produktiven Klasse bestimmen. Dies erfordert nicht allein der Gang der Darsteling, viehnetr füht die Geschichte marxistischer Klassentheorien vor Augen, dah selbst dieser von Marx aushihnichs behandelte Zusammenhang nicht selten unbegriffen blicb. So Z. B. esumiert Jirgen Kuczynski einige klassentheoretische Ausführungen (Varga, Ergcharin u. a.), wie sie auf dem 6 . Weltkongreb der KI vorgetragen wurden:

"Es besteht eine Tendenz im Stadiom des Imperialismus für das Industreproletarit, dio sich auch gelegentich in enzelnen Landen durchsetzt absolut abzunchmen. Ls bestent vise algemeine Tendenz im Stadium des Imperiapsrus fur das Industrieproletariat, die sich in alpeneren auch durchsetzt, relativ abzunchmen" (1).

Er vermerkt - zur Begrundung der geschilderten Tendenzen - Siationen, in de nen die "Produktivitat starker steigt als die Produktion" (2). Doch kann die Bewegung weder der industriellen noch der produktiven Arbeitsmassen auf der Basis dee so beschriebenen gegensätzlichen Momente (er meint wohl Freisetzung durch Ste:gerung der Arbeitsproduktivität einerseits, Attraktion produktiver Arbeiter çuagestiegenem Größenumfang des Produktionsprozesses andererseits) enkanm werden. Auch Kuczinskis Bezug auf spezifische imperialistische Bestimmungen als Gruadiage der von ihm reformulierten, allgemeinen Tendenz" bleben unausgewiesen (3). Sollte es sich hier um eine Entwicklung handeln, die ausschliebich ein imperialistisches Stadium, nicht aber die kapitalistische Produktionsweise insgesant charak. terisiert?

Nun, rekapitulieren wir die Herausbildung der produktiven Klasse, wie sie von

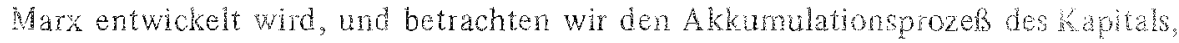
jenen Vermehrungsprozeß des Proletariats (4), zunächst (im wesendichen als Moment seines Produk tionsprozesses.

1) J. Kuczynski; Die Geschichto der Lage der Abciter unter dem Kapitalismus, Bd. 36, Berin (DDR) 1968, S. 129

2) ders.: a.a.O.,S. 123

3) Siche dazu auch seine ncuere Schrift: Klassen und Khssenkampfo, Fankfur 1972, wo dicser Zusammenhang sowie die Herausbildung der modernen Mittelassen als sperifisch-imperialistische Entwicklungen behauptet werden. Bei ihm wird douthoh, dat dort, wo die Akkumulationsbedingtheit herrschender Klassenstrukturen unbegriffen blebt, vorschnell die empirisch statistische, Vergewisserung" bemiht werden muts.

4) dazu MEW Bd. 23, S. 642 oder K. Marx: Resultate des unmitteloaren Produktionsprozesses, Verlag Neuc Kritik, Trankfurt $1970,5.86$ 


\subsection{Ursachen des Wachstums der produktiven Klasse}

Die in der Form des Mehrwerts angeeignete unbezahlte Arbeit -- wobei wir im folgenden von dem als Revenue verausgabten Teil abstrahieren -- wird in Kapital rückverwandelt: dies die Akkumulation des $\mathbb{K}$ apitals. Indem sich der kapitalisierte Mehrwert in konstantes Kapital zum Einkauf zusätzlicher Produktionsmittel, Rohmaterialien etc. und andererseits in variables Kapital zum Einkauf (5) zusätzlicher Arbeitskräfte teilt, schließt das Wachstum des Kapitals die absolute Zunahme der produk tiven Arbeiterzahl in sich ein. Wenn also diejenigen Momente systematisiert werden, die das Wachstum des Kapitals insgesamt erklären, wird zugleich erkannt, wie diese Momente den Zuwachs des variablen Kapitalteils und damit den Prozeß der Expansion der produktiven Arbeiterbevölkerung in Gang setzen (6). Dieser Prozeß ist im wesentlichen von zwei Faktoren abhängig:

1) von der bereits erreichten, vorgegebenen Kapitalgroßse und

2) von stofflichen Potenzen, die relativ unabhangig von der gegebenen Großse des Kapitals sind.

1) Das Wachstum der produktiven Klasse ist zunächst von der Größe des kapitalisierten Mehrwerts abhängig, wie sie einer bestimmten vorgegebenen Größe des Kapitals entspricht. Diese bestimmte Größe des durchschnittlichen produktiven Kapitals stellt eine bestimmte Anzahl gleichzeitig exploitierter A rbeitskräfte (V) dar, die multipliziert mit der gegebenen Mehrwertrate $(\mathrm{m} / \mathrm{v})$ (gegebene Intensität der Arbeit und Länge des Arbeitstags, gegebener Wert der Arbeitskraft) die Masse des Mehrwerts ergibt (7). Mit der so durch eine bestimmte Kapitalgröße gegebenen Masse des wiederum kapitalisierten Mehrwerts wächst auch der variable Bestandteil des Kapitals, wächst die produktive Arbeiterzahl absolut; hier zeigt sich das Wachstum der produktiv beschäftigten Arbeiterbevölkerung unmittelbar als Reflex der Wertbewegung, der Bewegung des Kapitals als sich selbst verwertender Wert.

2) Das Wachstum von Kapital und Arbeiterzahl wird aber zugleich bewirkt durch Potenzen, die relativ unabhängig von der Bewegung der Wertgrößen sind. Abgesehen von denjenigen Kräften, die der Kombination der menschlichen Arbeitsvermögen entspringen, abgesehen von wissenschaftlichen und natülichen Gratisressourcen des Kapitals (8), wollen wir uns auf die Differenz, zwischen der Maschine als wertbil-

5) Nicht zu verwechseh mit der Auszahlung des Lohns: das Cield fungiert hier als Zahlungsmittel. Dazu MEW Bd. 23, S. 563

6) Dabei muts aber gesehen werden, dats das Wachstum des variablen Kapitals und das der Zahl der produktiven Arbeiter vermittclte und keinesfals identische Bewegungen sind: Etwa die gewaltsane Herabsetzung des Arbeitslohns unter den Wert der Atbeitskraft kann bedeuten, dats u. U. cin gesunkener Lohnfonds Kapitalteil die gleiche Arbeiterzahl reprasentiert; dazu MEW Bd. 23, S. 626. Uberhaupt wird hier von der Lohrbewegung im ind ustriellen Zyklus abstrahiert, die in die Vermittlung von Kapitalwachstum und Wachstum der Arbeiterzahl eingeht.

7) dazu MEW Bd. 23, S. $321 \%$.

8) dazu MEW Bd. 23, S. $629 \mathrm{ff}$. 
dendes und produktbildendes Element" (9) konzentrieren: Die Erhohung der Produktivkraft der Arbeit, die sich wesentlich als zunehmender Umfang an Produktionsmitteln darstellt, mift sich an der Erhöhung der Masse der in einer bestimmten Zeit produzierten Gebrauchswerte, d. h. die lebendige Arbeit geht mit Hilfe der Produktionsmittel in gleicher Zeit über ein Mehr an Gebrauchswerten wertbildend hinweg; Wertmasse und Gebrauchswertmasse sind disproportional gewachsen.

Wird nun im Prozefs der Kapitalakkumulation der fixe konstante Teil des kapitalisierten Mehrwerts auf seine stoffliche Basis untersucht, so hat sich diese im Vergleich zu der des originalen fixen Kapitals (relativ) verbreitert. Da aber die zusätzliche Beschäftigung produktiver Arbeiter durch den Umfang der -- als Einsauger von lebendiger Arbeit fungierenden - Produktionsmittel bewirkt und bestimmt wird (10), reflektiert das Wachstum der produktiven Arbeitsbevölkerung hier den expandierenden stofflichen Bestandteil des Produktionsprozesses und nimmt mehr zu, als es allein dessen geschwollener Wertumfang zum Ausdruck brächte (11)...

\section{2 entgegenwirkende Momente}

Doch setzt sich die Entwicklung der Arbeitsproduktivität, eben noch positiver Faktor der Arbeiterakkumulation, zugleich in Widerspruch zur Form, worin sie erscheint: sie setzt der Kapitalakkumulation eine Schranke, indem sie hier als ein Moment der Reduktion der Arbeiterzahl wirkt. Der zunehmende Wirkungskreis der von der Arbeit in Bewegung gesetzten Produktionsmittel mißt sich zugleich daran, inwieweit er menschliche Arbeitskraft ersetzt und sich so dem Wachstum der produktiven Klasse entgegenstellt (12). Dieser Prozeß stellt sich im wesentlichen dar

1) als Verminderung der zusätzlichen Nachfrage und

2) als Freisetzung bereits beschäftigter produktiver Arbeitsmasse

1) Mit zunehmender Arbeitsproduktivität wächst der Umfang der Produktionsmittel pro Arbeitskraft (technische Zusammensetzung des Kapitals), wobei dieser Vorgang sich auf Grund der disproportional wachsenden Wert- und Gebrauchswertmassen in der Bewegung der Wertgrößen (wertmäßige Zusammensetzung) nur annähernd widerspiegelt. Nichtsdestotrotz wächst auch der variable Bestandteil des Kapitals verglichen mit dem Wachstum des konstanten Kapitalteils oder dem Wachs. tum des Gesamtkapitals in allein abnehmender Proportion (13). Der relativ zum

9) MEW Bd. 23, S. 408

10) dazu MEW Bd. 25, S. 258; wir konzentrieren uns hier auf das zentrale Bestimmungsnoment, die Produktionsmit tel, damit auf das fixe Kapital.

11) Dic so gemät dem gewachsenen Uniang der Produktionsmittel zusätzlich beschäftigten Arbeiter beschleunigen wiederum die Produktion von Mehrwert, damit den Akkumulationsprozes: Kapitalakkumulation und Arbeitsproduktivitat stofsen sich gegenseitig voran. Dazu MEW Bd. 23, S. 653

12) Dals auch mit der Intensivierung der Arbeit und der Verlängerung des Arbeitstags das Wachstum der produktiven Klasse auf Kosten der crhohten Ausbeutung der beschäftigten Arbeiter gehemmt werden kann, bleibt unberücksichtigt.

13) dazu MEW Bd. 23, S. $657 \mathrm{f}$. 
konstanten Teil des betrachteten kapitalisierten Mehrwerts sinkende variable Teil drickt so eine verninderte zusätzliche Nachfrage nach produktiver Arbeit aus. Dicse Verminderung der zusätzlichen Nachfrage nach Arbeitskraft wird durch die Zentralisation bereits gebildeter Kapitale und der durch sie beschleunigten Arbeitsproduktivitat noch verstärkt (14).

2) Nicht allein das akkumulierte, zusätzliche Kapital spiegelt die veränderte werto mäßige und technische Z Zusammensetzung, auch das alte Kapital erfährt mit der Zeit eine Umwälzung seiner stofflichen Basis. Auch hier vermag im Verlauf der Akkumulation eine geringere Arbeitsmasse eine größere Masse Maschinerie und Rohstoff in Bewegung zu setzen (15). Mit der Verminderung der zusätzlichen Attraktion produktiver Arbeiter stellt sich also die mit der Umwälzung des Originalkapitals einhergehende Repulsion bereits beschäftigter Arbeiter der Vemehrung der produktiven Arbeiterbevölkerung entgegen. -

So bleibt zu fragen, welche der beiden hier skizzierien streitenden Tendenzen sich im Fortschritt der herrschenden Produktionsweise durchsetzt, warum und unter welchen Bedingungen sich eine dieser Tendenzen durchsetat.

\section{3 beschleunigte Akkumulation als Bedingung des absoluten Wachstuns der produktiven Klasse}

Dazu ist es notwendig, die Bewegung der produkiven Klasse a umreiben. wie sie sich unter Einbezug der Ebene des Gesamtprozesses des Kapitals darstelit.

1) Die Vermehrung des relativen Mehrwerts qua Steigerung der Produktivkraft der Arbeit, d. h. die Ausdehnung der Mehrarbeitszeit auf Kosten der notwendigen Arbeitszeit durch den sinkenden Wert der die Arbeitskraft reproduzierenden Waren, wird um so schwieriger, je höher die Arbeitsproduktivität bereits entwickelt. ist (16), zum anderen wird die Vermehrung des absoluten Mehrwerts (A rbeiterzahl) durch die steigende organische Zusammensetzung reduziert, worin letzilich die sin. kende Proportion der unbezahlten Arbeit zum aufgewandten Gesamtkapital, der tendenzielle Fall der durchschnittlichen Profitrate begründet liegt. Mit dem tendenziell sinkenden Verwertungsgrad der Kapitale bleibt der Anreiz zur Fortsetzung der Akkumulation einzig durch die Steigerung der Masse des Profits erhalten, wobei die Gesamtmasse der einzelnen Profite gleich der Masse des Mehrwerts (16a), dessen beide ursprüngliche Faktoren, Wachstum der produktiven Arbeitsmasse und steigende Mehrwertrate, sich nicht erschöpfen dürfen.

Wenn nun aber eine Steigerung der Mehrwertmasse zusätzlicher A rbeitskräfte und damit eines wachsenden variablen Kapitalteils bedarf, so muß auf Grund der

14) dazu MEW Bd. 23, S. 656

15) dazu MEW Bd. 23, S. 658

16) dazu Grundrisse, S. $239 \mathrm{ff}$.

16a) Für die in diesem Aufsatz verfolgten Zwecke können diejenigen Modifikationen auburhalb der Betrachtung bleiben, die sich aus der Wert-Preis-Transformation ergeben. 
gestiegenen organischen Zusammensetzung des Kapitals und den mit dieser einhergehenden Nachfrageverminderungen und Freisetzungsprozesse das Gesamtkapital vergliohen mit seinem variablen Bestandeil uberproportional (sprich: beschleungt) zunehmen (17). Diese beshleunigte Akkumulation von Kapital ist wnaitio sine qua non des absoluten Wachstums der produktiven Klasse (18).

I) Sedoch werden die Bedingungen einer beschleunigten Akkumulation periodisch untergraben, womit auch periodisch ein absoluter Rükgang der produktiven Arbeiterzahl (andererseits ein Auffillen der industriellen Reserveamee) erfolgt. Diese Periodizitat meint einerseits den industriellen $Z$ yklus und andererseits die historischen Phasen der Akkumulation (19), in deren Verlauf die Bedingungen der beSchleungten Kapitalakkumulation und damit die Bedingungen der Expansion der produktiven Abeiterbevolkerung durch zunehmende Schwierigkeiten (a) der Mehrwertprodukion und (b) der Mehrwert realisation schwinden.

a) Wenn mit dem tendenziellen Fall der Profitrate allein eine Enöhung der Profit. masse den Gang der Akkumulation aufrechterhält, so fuhrt das dazu erfordentiche beschemigre Wachstum des Gesantkapitals an eine absolute Grenze heran, an der zu weng Mehriver produziert wird, um nochmals die Beschleunigung der Akkunu. laton aufrechtuerhalten und den sinkenden Verwertungsgrad nochmals durch wachsende profimasse zu kompensieren, $\mathrm{d}$. h. das akkumulierte Kapital ( $\mathrm{K}$, ) produciert nur ebensoviel Profitmasse, als es vor seiner Akkumulition in seiner alten Cestalt $\left(K_{1}\right)$ produziert hat $(20)$, was den Fall der Profitrate nun erst recint vorantreibt.

Det Eintritt in eine Periode eines derart sinkenden durchschnittichen Verwer. tungsgrades ergib sich in wesentlichen, wenn (a/1) die Erhöhung des einen Faktors der Mehrwentmasse, die Erhöhung oer Mehrwertrate, auf Grund der fortgeschrittenen organschen Zusammensetzung des Kapitals als Ausdruck der fortgeschrittenen Arbeitsproduktivität einen derartig hohen Aufwand von zuschüssigem Kapital erfordert, dak dieser Aufwand in keinem Verhälnis zu der uber die Wertsenkung der Arbeitskraft gewonnenen Steigerung der Mehrwertmasse stünde, und zugleich die Ausdehnung der Mehrarbeitszeit durch Arbeitsintensivierung, Streckung des Arbeitstags etc. an physische oder gewerkschaftlich erkämpfte Grenzen stieke. Ein Eintrit $t$ in diese Periode ergäbe sich zum anderen, wenn (a/2) der andere Faktor der Mehrwertmasse, die Zah der produktiven Arbeiter, auf Grund der hohen organischen Zusammensetzung, aui Grund einer fortgeschrittenen Kontraktion der Reser-

17) daru MYW Bd. 23, S. 477 and MEW Bd. 25, S. 232 t.

18) Absolutes Wachstam und relativer I all zum (iesantkapital (wie zur Gesamtbevolkerung) charakterisiert cbenso die Entwicklung der burgerl. Klasse, deren Heraubildung aber autrorhalb der Botraching bleibt.

19) Auf dic Vemitlung bejer Aspekte bratueht hier nicht eingegangen zu wercen. Siche dazu die Versuche Mandels: Der Spätkapitalismus, Frankfurt 1972. S. i01 fl, oder die Versuche Roth/Kanzows: Unwissen als Ommacht, Berlin 1970, S. 91-146. Ls versteht sich von selbst. dafs die folgenden Bestimmungen nicht di Konstizution des realen Krisenverlauls erkliren konnen.

20) dazu MLW Bu. 25, S. 261 
vearmeen, auf Grund zu langsamen Wachstums der Gesamtbevölkerung etc. nicht oder nur unzureichend gesteigert werden könnte.

b) Hier stellt sich die Schranke der beschleunigten Akkumulation als scheinbar gegensäzliche Tendenz dar: es wird zuviel Mehrwert produziert, der auf die engen Grenzen der Konsumtionskraft der arbeitenden Bevölkerung stoßend nicht voll realisiert werden kann (21), für eine beschleunigte Fortsetzung der Akkumulation also zu wenig kapitalisierbare Mehrwertmasse vorhanden wäre. (Die Vermittlung a/b wird an späterer Stelle aufgegriffen.) --

Mit dem Auftreten derartiger Konditionen der Akkumulation wird die sich historisch durchsetzende Tendenz der absoluten Ausdehnung der produktiven Arbeiterbevölkerung periodisch außer $\mathbb{K}$ raft gesetzt.

\subsection{Zusammenfassung}

Der bislang entwickelte Abriß zentraler, die Bewegung der produktiven Klasse be stimmender Momente macht einsehbar, daß eine periodische absolute Abnahme der produktiven Arbeiterbevölkerung und damit auch des Industrieproletariats (22) keinesfalls ein ,imperialistisches Novum" ist. Ebenso deuten die sich einem ungehemmten Wachstum der produktiven Klasse wirksam entgegenstellenden Faktoren bereits an, daßs die relative Abnahme der Arbeiterbevölkerung an der Gesamtbevölkerung durchaus nicht den spezifischen Bedingungen eines "imperialistischen Stadiums" verschuldet sein mußs, vielmehr durchaus eine die Klassenstrukturen der kapitalistischen Produktionsweise im allgemeinen kennzeichnende Entwicklung sein karnn. Letztendlich labt sich jedoch die relative Bewegung der produk tiven Arbeitsbevölkerung einerseits nicht ohne die Analyse der Bewegungsgesetze der anderen Klassen der burgerlichen Gesellschaft (dazu III. Teil) und auf den ersten Blick auch nicht in Abstraktion von den Bedingungen des Wachstums der Gesamtbevolkerung begreifen.

Letzteres, die weitgehende Abstraktion von der Gesamtbevölkerung, ist jedoch nicht willkürlich, sondern methodisch notwendig: zwar gewährt das Wachsium der Bevölkerung die Stetigkeit des Prozesses der Kapitalakkumulation, erscheint hier als eine Grundlage der Akkumulation (23), zum anderen aber wird umgekehrt die Entwicklung de: Somtbevölkerung wiederum nur als durch kapitalistische Akkumulation bestinmti Bewegung erklärbar (24); hier erscheint umgekehrt der historische Verlauf der Akkumulation als letztinstanzlich ausschlaggebende Grundlage der Vermehrung der Bevölkerung. Gegen Maithus' Theorie der natürlichen geometrischen Fortpflanzung reklamiert Marx den jeweils historischen Charakier der ,verschiedenen Gesetze der Vermehrung der Population und der Überpopulation":

dazu MFW Bd. 25, 5.254

22) Die Differenz beider Kategrorien ist hier uninteressant.

23) dazu MFW Bd. 26.2. S. 478

24) Ein Beispiel dieses Bestimmungsverhaltnisses liefert Marx etwa: MEW Bd. 25, \$. 228 f. 
,Lr (Malhus, NK) ist es, der abstrahiert von diesen bestimmen historischea (ieseqzen der Populationsbewegungen, dic da die Historia der Natur des Menschen: dic nabrichen Giseta sind aber nur natüriche (jesetze des Menschen auf bestimmter historischer lintwicklung. nit durch scinen cigenen (ieschichtsprozes bestimmter lintwicklung der Produktivkrafte" 25 )

Welche historisch-spezifischen Momente auch immer auf den faktischen Verlauf der Population der bürgerlichen Geselischaft insgesamt einwirken, Lebensnerv dieses realen Verlaufs und Ausgangspunkt seiner theoretischen Darstellung bleibt der Prozefs der Akkumulation.

25)

Grundrisse, S. 500

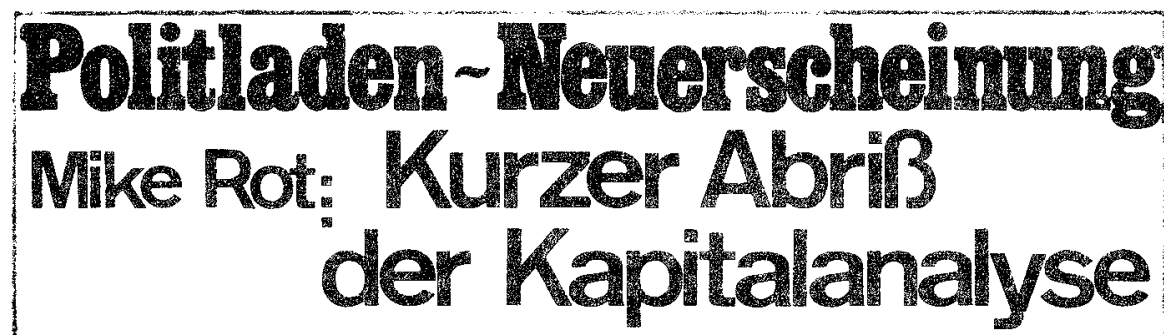

Lernmaterial für den ersten Durchgang durch Karl Marx ,Das Kapital" Band 1 - III mit knappem Stichwortregister zur Kapitalanalyse und einem Grundstock zu'nem Zetrelkasten (rausnehmbar)

Der Text ermögicht eine erste Übersicht über die Analyse der kapitalistischen Gesellschaftsform, die Karl Marx in seinem Hauptwerk vorgelegt hat. Er ist knapp und verständlich, auch wenn man bisher nicht im Kapital gelesen hat. Durch übersichtliche Zusammenstellung der wichtigsten Fachausdrücke soll das Herangehen ans Kapital erleichtert werden. Der Argumentationsgang der einzelnen Abschnitte ist auf "Lernkarten" festgehalten. Sie können ohne großen Aufwand durch Eirvarbeitung des Stellenregisters zu einem Grundstock für einen "Zettelkasten zur materialistischen Gesellschaftstheorie gemacht werden.

Der Text ist auch gedacht als Vorbereitung für in Kürze erscheinende Texte zum Kapital, wie Probleme des Klassenkampfs Sonderheft 6 . Löhnbergs Einführung zum Selbststudium des Kapital (Fischer). Karl Helds Schulungstext zu Kapital Band 1, sowie dem Text der SAZ Berlin.

Mai 1974

128 Seiten - 7,00 DM

POLITLADEN ERLANGEN 852 ERLANGEN POSTFACH 2849 
Karin Gumet Veriag - "Berlin 44, Postfach 106, Tol: 68426 28

A. und D. Prudhommeaux

Bewarintung des 3 olles

Autbau, Organisierung und Kämpfe der Voiksmiliz

in spanischen Bürgerkrieg

Einieitung Cart Euztein

Bo Seiten

$5,-D M$

Uirich Linse

Gustay Landauer und die Revolutionszeit $\$ 918 / 4919$

200 Seiter!

8.- $-\mathrm{BM}$

P. Arschinaff

Geschichye det Machno-Eewegang 19131921

Berichte und Dokumente der revolutionärer Bauernbewegung in der likraine

260 Seiten

$10-$ DM

J. Agnoli, C. Brendel, I. Mett

Die royolutionären Aktionen des russischen Arbeiter und Baturn -

Die Kommune von Krorastiadt
150 Seiten
6,- DM

Cajo Erendel

Adtoronze Klassenkämpíe ä: England 1945-1972

120 Seiten

$5,50 \mathrm{DM}$

Kollektivierung der industrie und Landwirtschaft

Die Soziale Revolution in Spanien 1936-1939

Dokumente. Berichte und Selbstdarstellungen der

sarnischen Arbeiter und Eavern

Einteitung Erich Gerlach

230 Seltent

$10,-\mathrm{DM}$

Amton Punckeat

Neutestimmung des Markismis -... Bd.

Diskussion über Arbeiter räte, Marxismus und Staat

130 Seiten

$6, \cdots D M$

Anarchismus urd Marxismus Bd. 2

F. Amilie

Anarchismus hetste - Theorie und Pra .s des Reproduktionsbereing

Y. Bourdat

Maksismus und Anarchismus

f. de jong

seinot Mark ais Anarchist?

13. a.

140 Seiten

6, - D D

Peter Heintz

Anstrchismus und Gegenwari

Positiver und negativer Anarchismus

144 Seiten

$6,-D M$

Unter sdem Pflaster biegt der Strand - Anarchismus heute

N. Chomsky

Anmerkungen zum Anarchismus - Rarlikaier Marxismus und konse-

quenter Anarchismus

Ch. Dericurn

Absage an die Gewalt

M. Bookchin

Wör zu, Markist!

H.P. Duerr

Unter dem Pflaster liegt der Stranci

P. Feverabend

Thesen zum Anarchismus 1973

160 Seiten

8. $-O M$
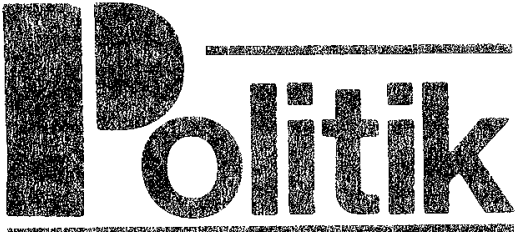

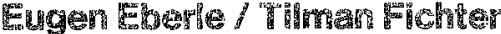

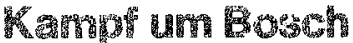

Eine dokumentarische intersuchung der KPDBetriebspolitik nach 1945 am Beispiel Bosch: Volksfromt in den Stadtelen oder Einheitsfront in den Betrieben? Entnazfizierung oder Mitarbeit in den Spruchkammern? Weiche Konsequenzen hatte die wiederaufgenommene RGO-Politik?

Pellitik 50, 192 Seiten. DM 7,50 $(6,50)$

\section{Sarn}

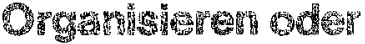
mathister Warden

Vorschlage fü Genossen links unten

Politik 39. 96 Seiten. DM 4,50 $(3,50)$

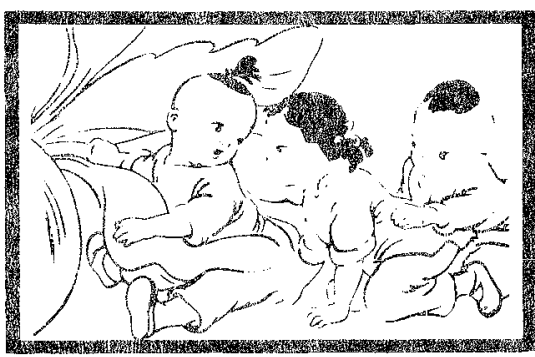

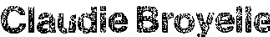

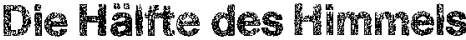

Frauenemanzipation und Kindererziehung in China. Mit einem Vorwort von Han Suyin Polititu 49.176 Seiten. DM $7,50(6,50)$

\section{Amo Münsster Chlle - friedlicher Weg?}

Historische Bedingungen, "Revolution in der Legalitätt", Niederlage

Politik 44. 224 Seiten. DV $7,50(6,50)$

Jedes Buch ist im Abonnement 1 Mark billiger. Wenden Sie sich bitte an thren Buchhändler oder an den Verlag: 1 Berlin 3 , Jenaer Str. 6 


\section{Teil}

\section{Zur Herausbildang der Mittelklassen im kapitalistischen Akkumulations- prozes}

Forbemerkung: In dieser Arbeit kann weder auf den widerspruchlichen Werdegang der Herausbildung der Kategorien produktive/unproduktive Arbeit bei Marx noch auf die Kontroverse um die reproduktionsanalytischen Relevanzen dieser Kategorien eingegangen werden, wie sie zwischen Autoren wie Altvater. Huisken. Mandel. Mattik, Cogoy u. a. gefuhrt wird (1). Um das in diesem Teil gesteckte Ziel, die Herausbildung der modemen Mitteklassen, zu begreifen, genügt es zunächst, wenn wir darüber Verstandigung erlangen, welche Bereiche der Gesamtbevolkerung im folgenden betrachtet werden:

Restimmen wir die Fomen menschlicher Arbeit, wie sie sich in den Reproduktionszusammenhängen auf cer Ebene des Gesamtkapitals darstellen, so geht die Zirkulationsarbeit auf dieser Ebene in den Bereich der unproduktiven Gesamtar. beitskraft ein, da sie die Formbestimmtheit der produktiven Gesantarbeitskraft, mehrwertproduzierende Arbeit zu leisten, nicht erfült. Die innere Formdifferenziertheit der unproduktiven Gesamtarbeitskraft und die Aufschlusselung ihrer inmeren Klassen- und Schichtenstrukturen bleibr zunächst unberucksichtigt, vielmehr interessiert hier allein die Gemeinsamkeit, die sie in der Quelle ihrer Revenuen findet:

Das gesellschaftliche Gesamtprodukt stelle sich wertmäßig dar als $G=M+C+V$ (wobei $M$ gleich der gesamten Mehrwertmasse, $C$ gleich dem Gesantwert der sachiichen Produktionsfaktoren und $V$ gleich dem Wert der produktiven Gesamtarbeitskrafi). Die diversen Revenuen der (im unfassenden Sinn) unproduktiven $\mathrm{A}$ rbeit leiten sich dabei aus $M$ und aus $V$ ab:

a) Aus $V$, weil ein Teil der unproduk tiven Arbeitsfunktionen (etwa im Gesundheitswesen, Bildungswesen etc.) zur Produktion und Reproduktion des produktiven Arbeitsvermögens taugt oder gar ausschliefslich dazu dient, so dah ein Teil des Lohns der produktiven Gesamtarbeitskraft zum Erwerb die. ser Dienste (direkt oder indirekt etwa als Steuer) verausgabi werden mus. $\checkmark$ setzt sich in dieser Hinsicht zusammen aus $v+u(v)$.

b) Aus M, da der restijche Bereich der unproduktiven Arbeitsfunktionen (Zirkulationsarbeit: Gewährleistung staatlicher Rahmenbedingungen der Produktion, die nicht in die Reproduktion der produktiven Arbeitskraft ein-

1) Verwiesen wird auf zwei neacre Veröfentlichungen, in welchen die Kategorie der produktiven Arbeit mal in einer weiten (Projekt Klassenanalyse: Materialien ... a. a. $\mathrm{O}$., S. $202 \mathrm{ff}$ ) und mal in einer engen liassung (Rudi Schmiede: Grundprobleme der Marxschen Akkumulations- und Krisentheorie, Frankfurt 1973, S. 30 ff.) begründet wird. Wenn auch nicht in allen Bestimmungen, wird doch der betzten Auffassung zuzustimmen scin. Die - meiner Kenntnis nach - stringenteste Interpretation der Kategoricn produktive/unproduktive Arbeit auf jeweils spezifischen Ebencin der Kapitalreproduktion und der Bedeutung stofflicher Bestimmungen (reproduktive/unreproduktive Waren) zum Bogrift dieser Kategorien findet sich bei Mario Cogoy: Wertheoric und Staatsalagaberi; in: Braunmühl u. ia.: Probleme einer materialistischen Statstheorie; Frankfurt 1973 
gehen; von der Klasse des Kapitals erworbene Dienstleistungen etc.) emzig im Mehrwert die Quelle seiner diversen Revenuen finden kann. M setzt sich in dieser Hinsicht zusammen aus $m+u(m)$.

Die unprodukiive Gesamtarbeitskraft repräsentiert so über ihre abgeleiteten Revenuen die Wertgröke $U=u(v)+u(m)$. Im folgenden wird also derjenige Teil der Gesamtbevoikerung betrachtet, dessen Revenuen in $1 /$ eingehen, wobei es zunächst gleichgültig ist, ob die jeweiligen unproduktiven Arbeiten die Form der Lohnarbeit annehmen oder nicht. Ebenso gleichgültig ist es zunächst, ob die Bezieher dieser Revenuen tatsachlich im gesamtgescllschaftlichen Arbeitsprozets wirken oder nicht. d. h. allein als unproduktive Konsumenten fungieren. - Diese einheitliche Betrachtung der unproduktiven Gicsamtarbeitskraft kann - wie bereits erwähnt -- nicht die Konstruktion einer einheitlichen Klasse implizieren, sie ist vielmehr zunächst notwendig, um die Bedingungen zu entwickeln, denen das Wachstum dieser Bevölkerungsschichten unterliegt.

\section{I Grossmann und Gillman - Akkumulation als Schranke und Motor des Wachstums der Mittelklassen}

Un die Bewegung der modemen Mittelklassen der bürgerlichen Gesellschaft als Resultat und Bedingung der Akkumulation von Kapital zu begreifen, muk an denjenigen Bestimmungen angeknüpt werden, die in die Entwıkklung der produktiven Klasse eingingen. Es wurde skizziert, warum das absolute Wachstum dieser Klasse die beschleunigte Akkumulation erforderte, deren Bedingungen aber im Verlauf der kapitalistischen Produktionsweise periodisch durch zunehmende Verwertungs- und Realisierungsschwierigkeiten untergraben werden. Doch konnte bislang das Verhältnis von Mehrwertproduktion und Mehrwertrealisation unvermittelt bleiben, da es für die Analyse der Vermehrung der produktiven Arbeiterbevölkerung von geringerer Bedeutung war; von weleher Relevanz dieses Verhältnis jedoch für die Analyse der Wachstumsbewegungen der Mittelklassen ist, soll zunächst an zwei gegensătzlichen Konzeptionen der marxistischen Akkumulationstheorie deutlich gemacht werden.

Die um die Jahrhundertwende aufkommenden Imperialismustheorien Hilferdings, Kautskys, Luxemburgs, Bucharins u. a., wie divergent auch inmer die Positionen waren, werden für Henryk Grossmann in zweifacher Hinsicht charakterisierbar, in ihrem gemeinsamen Manko, (a) einerseits ein mehr oder minder äußserliches Verhaltnis zur Methode der politischen Ökonomie zu haben, und (b) damit andererseits der inneren Akkumulationsproblematik verständnislos gegenüberzustehen (2). Die innere Widersprüchlichkeit der Kapitalakkumulation besteht für Grossmann in dem bereits umrissenen Zusammenhang zunehmender Verwertungsschwie rigkeiten,

2) Grossmann: Das Akkumulations- und Zusamnenbruchsgesetz des kapitalistischen Systems, Frankfurt 1970, insb. (a) S. $79 \mathrm{ff}$. und (b) S. $117 \mathrm{ff}$ : auf sein Verständnis der Methode der politischen Ökonomic als "Annäherungsverfahren" und die partiellen Mängel seiner Konzeption der Ubberakkumulation kann allenfalls indirekt eingegangen werden. 
Schwierigkeiten der Mehrwertproduktion, wo der tendenzielle Fall der Profitrate ab einem bestimmten Zeitpunkt nicht mehr durch das absolute Wachstum der Profitmasse kompensiert werden kann, da deren zwei ursprungliche Faktoren, Mehrwertrate und Arbeiterzahl, unter bestimmten Bedingungen zu erschöpfen drohen, so dafs es zu einem Überfluß des in nun nicht mehr produktiv anlegbaren Großen produzierten Kapitals und andererseits zu einem Überfluls an Bevolkerung, zur Expansion der Reservearmee etc. kommt (3).

Grossmann nun sieht die Expansion der Mittelklassen als einen Faktor an, der diese Zusammenbruchstendenz verschärft:

„Durch die Existenz dieser, aus der kapitalistischen Produktionsueise selbst entstehenden Mittelschichten wird... die Verwertungsrate des gesellschaftlichen Cesamtkapitals verschlechtert, daher die Zusammenbruchstendenz notwendig verschärt, unabhangig von dem Unstand, ob dicse Mittelschichten politisch die Herrschaft des Kapitals zunachst betestigen. Wachsen diese Mittelschichten, so muli sich auch dic Zusammenbruchstendenz verschärten" (4).

Grossmann tendiert dazu, das Wachstum der Mittelklassen einzig als Schranke der Akkumulation zu begreifen, dieses Wachstum als zugleich notwendige Voraussetzung der Akkumulation gerät aus dem Kreis der Betrachtung und macht einem vorschnellen Verweis auf vermeintliche politische Implikationen dieser Entwicklung Platz.

Reduziert einerseits die Ausdehnung der unproduktiven Arbeitsmasse die Wachstumspotenz der produktiven Arbeitsmasse, letztere ist etwa durch vermindertes Wachstum der Gesamtbevölkerung ohnehin eingeengt (siehe 3.4), also einen der ursprünglichen Faktoren der Mehrwertproduktion, so wird andererseits die fur die Fortsetzung der beschleunigten Akkumulation notwendige bestimnte (Minimal-) Größe der Mehrwertmasse dadurch in Frage gestellt, dak der Konsum des unproduktiven Bevölkerungsteils auch auf Kosten des Mehrwerts geht.

„Durch thren Konsum (soweit dicser nichit auf Kosten der Arbeiterkiasse, also aus dem Lohne v erfolgt) wird der Mehrwert, also die für die A kkumulation verfügbare Quelle vermindert" (5).

In der Tat wird vom Standpunkt der bloßen Verwertungsproblematik die Expansion der Mittelklassen nicht erklärbar, denn gemäß dieser Logik suchte das Kapital die Vermehrung dieses Bevölkerungsteils zu reduzieren wo es nur ginge, um ja nicht seine Akkumulationsbedingungen zu schmälern. So verwundert es nicht, wenn Grossmann zur Konsequenz gelangt, daß ,die Zusammenbruchstendenz ... durch die Verminderung dieser Personenzahl abgeschwächt werden" könnte, obwohl er die engen Grenzen einer solchen Verminderung erkennt (6). Wir werden noch sehen, daß eine Konzeption der Kapitalbewegung, wie sie bei Grossmann vorliegt (7), nur einen Aspekt der Mittelk lassenproblematik zum Ausdruck bringen kann. -

3) ders.: a. a. O., S. 125 ff.; dazu auch MI:W 25, S. 257-270

4) ders.: a. a. O., S. 355

5) ders.: a. a. O., S. 359

6) ders.: a. d. O., S. 361

7) In abgeschwachter form gilt diese Kritik auch Paul Mattik: Marx und Keynes, Frankfurt 1969, der aber zunächst auterhalb der Betrachtung bleibt. 
Über seine empirische Analyse des tendenziellen Falls der durchschnittichen Profitrate gelangt J. M. Gillman zu einer der Grossmannschen Konzeption entgegengesetzten Position. Wie bereits gesagt, fallt die Profitrate letztlich durch das anumenische Verhälnis, in dem Mehrarbeitszeit und Arbeitsproduktivität wachsen, oder anders ausgedrückt, die organische Zusammensetzung des Kapirals als Ausdrick der zunehmenden Arbeitsproduktivität steigt schneller als die $\mathbb{R}$ ate des Mehrwerts und reduziert das Wachstum der Arbeiterzahl, weshalb insgesamt die unbezahlte Arbeit relativ zum aufzuwendenden Gesamtkapital fällt. Hauptsächlich auf Grund kapital sparender neuer Technologien (8), meint Gillman nun, weise die organische Zusanmensetzung ungefähr seit dem Ende des ersten Weltkriegs nicht mehr jene Steigerungsrate auf, die den Fall der Profitrate bewirken wiirde, so dat die Kapitalakkumulation nicht durch zunehmende Verwertungsschwierigkeiten, durch Mangel an Mehrwertmasse, sondern durch zunehmende Realivienungsschwierigkeifen der produzierten Mehrwertmasse charakterisiert werden könne:

„Dic Sehwicrigkeit, der These zu folgen, dats in der Periode des Monopolkapialismus das Problem der sinkenden Profitrate in erster Linie cin Problem der Rcalisation des Nettomehewerts (Mebrwert minus unproduktivem Ausgabentonds, NK) wird, entsteht aus der Tatsache. dah die Marxisten traditioncllerweise Marx gefolgs sind und dazu neigten, das Problem de: sinkenden Profitrate hatuptsachlich mit der Schaffung des Mehrwerts atuszud rücken" (9).

Gillman nun will die inneren Widerspruche der Akkumulation von Kapital auseiner sich verstärkenden Realisierungsproblematik erklären, wobei der , nicht investierbare Monopolprofit" für ihn die auswuchernde unproduktive Verwendung von Mehrwert zur Folge hat, sei es als Konsumfonds der unproduktiven Bevolkerungsklassen, sei es als Expansion der Kriegs- oder Luxusproduktion etc.:

.. Unproduktive Ausgaben werden zur conditio sine qua non für die lirhaltung der kapitalistischen Lebonsfähigkeit in der Lpoche des Monopolkapitalismus und hoher Monopolgewinnc" $(10)$.

Im Gegensatz zu Grossmann wird hier die Ausdehnung der unproduktiven A rbeitsmassen keineswegs als Schranke, vielmehr als unumstößliche Bedingung für den Fluß der Akkumulation angesehen (11).

Obwohl eine intensive Auseinandersetzung mit Gillman in diesem Aufsatz micht notwendig ist (12), wird ein Aspekt seiner Argumentation aufgegriffen, der sich in verwandelter Form auch bei anderen Autoren (Offe; Mandel) wiederfinden läßst:

8) dazu MEW Bd. 25, S. 245 í. über die Vewohlfeilerung der Elemente des konstanten Kapitals.

9) J. M. Cillman: Das Gesetz des tendenziollon lalls der Profitrate, liankfurt 1969, S. 103

10) ders.: a. a. O., S. 194

11) In abgewandelten formen tindet sich dieser Zusammenhang, wie er bej Gibman geschildert wird, bei Sweezy, Baran, Moszkowska u. a. wieder.

12) Siehe dazu P. Mattik: Werttheorie und Kapitalakkunulation, in: Kapitalismus und Krise (Hrsg. C. Rolshausen), liankfurt 1970 in bezug auf das Realisationstheorem und C. Deutschmann: Der linke Keynesianismus, Frankfurt 1973, S. 148 ff. sowie R. Schmiede: Grundprobleme . . . a. a. O., S. 153 ff. in bezug auf kapitalsparende Techologic. 
Die Fomel, in der Marx die Gesetzmaßrigkeit des tendenziellen Falls der durchschnitlichen Profitrate fakt, müse unter den Bedingungen des Monopolkanitalismus geandert werden, statt $\mathrm{m} / \mathrm{c}$ nun $\mathrm{m}-\mathrm{u} / \mathrm{c}$. (Die Abstraktion von $\mathrm{v}$ kann her unberücksichtigt bleiben, sie beruhrt das Problem nur ge ring figig.) Diese Anderung ergebe sich zwingend durch die qualitativ neue Rolle des unproduktiven Konsums in der Epoche des Monopolkapitalismus, während, Marx die entsprechende Frage nach den umproduktiven Ausgaben in Bezug auf de zyklischen Krisen und auf die Notwendigkeit von ubermäłigem Mehrwert ziemlich fluchtig behande ln konnte, da in seiner Epoche die Ausdehnung des unproduktiven Konsums oder der unprodukiven Klassen zwar moglich gewesen sei, aber keine "dringende Nowwendigken" darstelle (13). Doch allein das Unvermögen, zu begreifen, welche me thodische Notwendigkeit Marx dazt veranlakt, die unproduktiven Konsumtions- und Arbeitsprozesse weitgehend auferhalb der Analyse des Kapitals im allgemeinen zu lassen, herscht Gilman den Endruck auf, als spicie der mproduktive Fonds im Gegensatz zu Marx' Zeiten in der fortgeschrittenen kapitalistischen Gesellschaft okonomisch eine qualitativ neue Rolle: Es handelt sich beim Fall der Profitrate nicht darum, ,dak die Formel geandert werden muß, mit der die Verhälnisse in der Vergangenheit berechnet worden sind" (14), sondem um eine GesetzmäBigkeit, deren Wirkungsweise und Ërcheinungsformen auf reelleren Ebenen der Entfaltung des Kapitals Modifikationen erfahren, die außerhalb des allgemeinen Begriffs des Kapitais blieben.

Schon allein die wiederholten Verweise bei Marx auf die unumstöliche Not wendigkeit der Ausdehnung unproduktiver Konsumtions-und Arbeitsprozesse (15) lassen bezweifeln, daß diese Prozesse einen qualitativ veränderten Starus im Gesamtreproduktionsprozeß3 des Kapitals eingenommen haben - eine Frage, die letztlich durch den Einbezug der kategorialen Analyse der historischen Verlaufsformen dieser Prozesse zu beantworten sein wird. --

Vergleicht man die beiden Konzeptionen, wie sie hier stellvertretend bei Grossmann und Gillnan beschrieben wurden, so erscheint es auf den ersten Blick, als würde, je nachdem unter welchem Aspekt die innere Widersprüchlichkeit der Akkumulation entwickelt wird, als Realisations- oder Verwertungsproblem, der Expansion der unproduktiven Bevölkerungsteile, der Ausdehnung der modernen Mittelkkassen, mal qua Akkumulation ein Stachel versetzt (Gillman), mal qua Akkumulation eine Grenze gecogen sein (Grossmann). Diesen Zusammenhang gilt es im folgenden zu entwickeln.

13) Gilman: Prosperitä in der Krise, Frankfurt 1968, S. 32

14) ders.: Das Gesetz ..., a. a. O., S. 193

15) Ein wilk kurlicher Verweis a uf markante Passagen mag hier genugen: Resultate des unmittelb. Proúuktionsprozesses, S. 71; MEW Bd. 26.2, S. 493

16) Mattik: Marx..., a. a. O., S. 73 f.; scin ,Model1"begriff und die Bestimmung der Mehrwermasse als Motor des Akkumulationsverlaufs katn hier nur indirekt kritisiert wercen. 


\subsection{Bemerkungen zum Problem der Überproduktion}

Doch zuvor muk kurz. auf den Aspekt der Realisierung des Mehrwerts eingegangen werden, auf die Bedeutung, die dieser Aspekt im Konstitutionsprozek des realen Krisenverlaufs hat. Dazu verhilft uns die in der Tradition Grossmanns entwickelte Kritik Pau! Mattiks an unterkonsumtions- und disproportionalitätstheoretischen Konzeptionen:

Mattik ist der Ansicht, ,der Akkumulationsprozeß selbst hebt den Fall der Profitrate auf", und zwar bis zu einem bestimmten Punkt:

,Zur ihrem , logischen Lnde gedacht, würde cine ständig sich beschleunigende kapitalexpansion den relativen lall der Profierate wegen eines Mangels an Mchrwert, bezogen auf die angeschwolkene Kapitalmasse, in einen absoluten 1 all verwandeln. Wenn dies geschähe, würde die Wirklichkeit mit dem Modell der Kapitalexpansion ubereinstimmen" (16).

Das nun nicht mehr akkumulierbare, brachliegende Kapital reicht nun also nicht mehr aus, um Investitionen zu tätigen, welche die Profite der einzelnen Kapitale wesentlich erhöhen könnten, so daß für die Kapitale die erweiterte Nachfraga nach Produktionsmitteln, Rohstoffen und Arbeitskräften unterbleibt. Ebenso kommt es mit der Freisetzung von beschäftigten Arbeitskräften und der dadurch bedingten Senkung der Arbeitslöne zu einem Nachfragemangel nach Konsumtionsmitteln. Unzureichende Realisation von Mehrwert, d. h. Überproduktion von Waren wird derart verursacht von Mattik als untergeordnete Folge von Überakkumulationstendenzen (Fall der Profitrate) begriffen - auch wenn dieser den Krisenverlauf begründende Zusammenhang nicht als solcher in Erscheinung tritt:

„Der sich ergebende Mangel an Nachfrage crscheint als Uberproduktion von Waren und suggeriert auf dicse Weise, dats das Realisationsproblem dic Ursache der Krise sei“"(17).

Mattik tendiert dazu, Ủberproduktionstendenzen einzig als bloße Erscheinungsform sich zuspitzender Verwertungsschwierigkeiten zu begreifen, die Realisation des Mehrwerts wird einzig zu einem, ,Problem der konkreten Marktlage, nicht der abstrakten Wertanalyse" (18).

In diesem Rahmen kann verständlicherweise nicht entwickelt werden, wie die allgemeinen Widersprüche in der Bewegungsform des Kapitals auf die Ebene der realen Konkurrenz drängen und den industriellen Zyklus konstituieren (19). Vielmehr genugt es hier, daß Problem der Mehrwertrealisation und Überproduktion (in groben Umrissen) bis zu dem Punkt zu entwickeln, der uns die Bewegung der

ders.: Werthcorie ..., a. a. O., S. 25 und ders.: Marx ..., a. a. O., S. $87 \mathrm{f}$

ders.: Wertheorie ..., a. a. O., S. 15

19) Ausührlicher und genauer werden die Bedingungen der Oberproduktion und der Überakkumulation etwa bei Semmler/Hoffmann: Kapitalakkumulation, Staatseingriffe und Lohnbewegung, in: PROKLA 2/1972 oder bei Freiburghaus/Müller: Zur Struktur des Krisenproblems bei Karl Marx, MEHRWERT 5/1973 untersucht. - Vereinfachend wird in dieser Arbeit als Überproduktion nur die Überproduktion von Produktionsmitteln und Konsumtionsmitteîn bezeichnet. Überproduktion von Kapital (Plethora von Kapital), die dem Fall der Profitrate verschuldet ist, bezeichnen wir als Überakkumulation von Kapital. 
Mittelklassen begreifen läßt:

1. Wenn Marx davon spricht, daß der einzige Zweck des Kapitals, das Vorantreiben der Mehrwertproduktion, von der spezifischen Konsumtionskraft der bürgerlichen Gesellschaft absehe, ,Konsumtionskraft auf Basis antagonistischer Distributionsverhälnisse (zu sein; NK), welche die Konsumtion der großen Masse der Gesellschaft auf ein nur innerhalb mehr oder minder enger Grenzen veränderliches Minimum reduziert" $(20)$, so betrachtet er in derartigen Formulierungen die Schranken der Mehrwertrealisation (die hier zunächst eine Schranke der Realisation des Werts von Konsumtionsmitteln sind) keineswegs als ein "Problem der konkreten Marktlage“ (Mattik) oder als ein sekundäres Folgeproblem der Überakkumulation von Kapital (dazu 2). Die Möglichkeit der Überproduktion (in diesem Fall von Konsumtionsmittein) ist im Gegentell ein im unmittelbaren Produktionsprozeß des Kapitals konsti. tuiertes Moment: die größtmögiiche Auspressung von Mehrwert, die Einengung des Werts der produktiven Gesamtarbeitskraft durch die Steige rung der Produktivkräfte konstituiert die Beschränktheit der Konsumtionskraft der Massen, konstituiert die Möglichkeit der Überproduktion von Konsumtionsnitteln. Diese Beschränktheit der Konsumtionskraft der Massen tritt dem Kapital in seinem Zirkulationsprozeß als ein Tauschzentrum gegenüber, daß der Realisierung de r produzierten Warenwerte Schranken setzt, da die exploitierten Lohnarbeiter ihn nun als Warenkäufer gegenüberstehen, deren Tauschfähigkeit sich tendenziell erschöpft (21).

Ohne weiter zu verfolgen, welche konkreteren Formen diese Tendenz zur Überproduktion annimmt, wird einsehbar, daß das Problem der Realisation von Mehrwert keinesfalls von uritergeordneter Bedeutung ist und aus der, Wertanalyse herausfällt". Vielmehr käme es in der ,abstrakten Wertanalyse“" (Mattik) darauf an, die Genese und die allgemeinen Bedingungen der Überproduktion (Tauschfähigkeit der Lohnarbeiter, mögliche Disproportionen der Produktionssphären. Geld als Mals des Werts und als Realisierung des Werts, die Bewegung des Kredits etc.) ausgehend vom unmittelbaren Produktionsprozeß bis hin zu den realen Prozessen der Konkurrenz nachzuvollziehen (22). - Doch halten wir fest, was in diesem Zusammenhang wichtig ist: mit der permanent beschnittenen Tauschfähigkeit der produktiven A rbeiterbevölkerung und der sich damit herausbildenden Tendenz zur Überproduktion (von Konsumtionsmitteln) wird es für das Kapital zu einer unumgänglichen Bedingung, in den realen Distributionsverhältnissen Formen aufzufinden, die dieser Tendenz entgegenzuwirken haben. Und es wird zu zeigen sein, wie die Herausbildung von spezifisschen unproduktiven Klassen als eine Form fungiert, die der Überproduktion en tgegenwirken hilft.

Doch muß zunächst danach gefragt werden, welche Form die hier umrissene Tendenz zur Überproduktion im Rahmen der Überakkumulation von Kapital an-

20) MFW Bd. 25, S. 254

21) dazu Grundrisse, S. 305-325. Diese Schranke der Realisation bedeutet freilich nicht, dats die cinfache und erweiterte Reproduktion, wic im zweiten Band des "Kapital" dargestelt, kein periodisches Gleichgewicht finden. In unserem Zusammenhang geht es um die Bedingungen der Zirkulation bei steigender Arbeitsproduktivität (steigender Mehrwertrate, steigende organische Zusammensetzung etc.).

22) dazu MEW Bd, 26.2, S. 510 
nimmt:

2. Wir sahen bereits, whe das Kapital im Fortschritt der Akkumulation eine Ausdehnung erreicht, bei welcher der sich verschlechternde Verwertungsgrad der Fortsetzung der Akkumulation eine Schranke setzt, d. h, der tendenzielle Fall der Profitrate wird hurch die ausbleibende Steigerung der Profitmasse verstäkt. Die Krise hat nun a!s Uberakkumulationskrise den Widerspruch von Kapitalexpansion und Protitrarenfall auszutragen, indem sie insbesondere

a) durch Lmwertung der vorhandenen Produktionsmittel, durch Brachlegung von Teilen des Gesamtkapitals, durch Entwertung des Warenkapitals (Produktionsmittel, Rohstoffe, Konsumtionsmittel) etc. und

b) durch Maknahmen zur Sieigerung der Mehrwertrate (Senkung der Arbeitslohne, Erhohung der Arbeitsproduktivität qua Einführung neuer Maschinerie etc.)

Ge Verwertungsbedingungen des Kapitals neu zu gestalten sucht (23). Der weitere Verlauf von Belebung und Aufschwung der Akkumulation, obwohl er wesentlich durch den realen Charakter der Krise bestimmt ist (24), beruht auf ihrem Resultat: die nun produzierte Mehrwertmasse kann sich an einem verminderten Umfang des Gesamtkapitals messen, die jetzige Profitrate ist verglichen mit derjenigen vor Einritt der Krise gestiegen.

Da die Uberakkumulation von Kapital stets die Überproduktion von Waren einschlier (25), erscheint die Schranke der Realisation des Mehrwerts hier als ein verursachtes Moment der Überakkumulation: neue Kapitalanlagen unterbleiben, da der geringe Umfang, in dem sie getätigı werden konnen, kein bedeutsames Mehr an Profit verspricht: das Kapital vemag nicht länger, sich seine eigene Nachfrage zu produzieren, $\mathrm{d}$. h. bereits prodnzierte Produktionsmittel und Rohstoffe bleiben ungekauft; beschäftigte Arbeiter müssen auf Grund der verschlechterten Geschäftslage freigesetzt werden, die Reservearmee dehnt sich aus und hat eine Kontraktion des Lohnfonds zur Folge, so dah die Krise auf Abteilung, I übergreift ... Wie auch inmer der reale Krisenverlauf aussehen wird, die oben entwickelte Tendenz zur Überproduktion tritt hìer als der Überakkumulation verschuldete Erscheinungsform auf, die hier gesetzten Schwierigkeiten der Mehrwertrealisation sind unmittelbar durch die Uberakkumulation von Kapital verursacht. Die ungenügende Realisation von Mehrwert ist gewissermaken die Kehrseite der ungenügenden Produktion von Mehrwert. So gilt es für das Kapital, nicht allein die Schranke seiner Verwertung durch die Neugestaltung der Profitrate zu überwinden, sondern zugleich wird die Schranke seiner Realisierung zu durchbrechen sein: so wie einerseits die Entwertung der Konsuntionsmittel der beschränkten Konsumtionskraft der Massen entgegenkommt und den Prozeß der Realisation auch in Bezug auf dieses Tauschzentrum wieder in Gang zu setzen sucht, so bedarf es zur Überwindung der Überproduktion (von in diesem $F$ all Konsumtionsmitteln) wiederum realer Distributionsformen,

23) dazn MEW Bd. 25, S. 262 ff und MEW Bd. 26.2, S. $496 \mathrm{f}$.

24) dazu F. Oelhner: Die Wirtschaftskrisen, ND Frankfurt 1971, S. 94 î.

Die strukturelle Bedeutung der staatlichen Finanz- und Wirtschaftspolitik für die Verursachung, Modifikation und Überwindung des realen Krisenverlaufs kann hier unberücksichtigt bleiben.

25) dazu MEW Bd. 25, S. $261 \mathrm{ff}$. 
welche die Beschränktheit der Konsumtionskraft der Lohnarbeiter kompensieren helfen.--

Man mußs also keiner unterkonsumtions- oder dispropotionalitastheoretischen Sackgasse verfallen, wenn man gegen Mattik entwickelt, daß die Überproduktion von Waren, die Schranken der Mehrwertrealisation, keine untergeordneten Erscheinungsformen der empirischen Konkurrenz sind, daßs es für den Fluß der Akku. mulation eine unumgängliche Bedingung ist, die Barrieren im Prozeßs der Mehrwert realisation niederzureißen. Die gewichtige Bedeutung der Uberproduktion von Wa. ren in der hier umrissenen Weise zu begreifen, bedeutet keineswegs, die eigentliche historische Beschränktheit der kapitalistischen Produktionsweise, wie sie sich im Fall der durchschnitrlichen Profitrate und in der Überakkumulationskrise des Kapitals zuspitzt, zu verkennen (26).

Es ist nun darzustellen, wie sich das Kapital u. a. in der Bewegung der Mittelklassen eine Form schafft, in der es diese Widersprüchlichkeiten der Akkumulationsbewegung auszutragen sucht.

\section{3 materielle Basis des absoluten Wachstums der Mittelklassen}

1. Der Antagonismus der kapitalistischen Distributionsverhältnisse bringt -- wie oben dargestellt - zum Ausdruck, dab die produktive Arbeiterbevölkerung ein tendenziell unzureichendes Tauschzenirum des Kapitais ist, da jegliche Erhöhung ihrer Konsumtionskraft einen Angriff auf den einen der beiden urspringlichen Faktoren der Mehrwertmasse, einen Angriff auf die Mehrwertrate darstellt. Nun mïssen zwar die Realisationsprozesse des Mehrwerts auf der Basis antagonistischer Distributionsverhältnisse ausgetragen werden, doch sucht sich dieser Antagonismus in der Entwicklung konkreterer distributiver Formen auszugleichen. Eine Form der Ausgleichung (29) ist die Bewegung von unproduktiven Mittelklassen,

„Klassen, dic nicht produzieren, sondern von ihrer Revenue teben, also miz̀ dem Kapital austauschen; Tauschzentren für es bilden" $(30)$.

Die ökonomische Funktion dieser Klassen als unproduktive Konsumenten: Käufer zu sein, ohne Verkäufer von Waren zu sein (31), obwohl sie (a) perpetuellen Charakter hat, erlangi sie doch (b) auf dem Hintergrund der Überproduktionskrisen besondere Relevanz:

26) ebenda, S. 260 und Grundrisse, S. 634

27) entfällt

28) entfällt

29) Vom Kapital als seinem eigenen Tauschzentrum, von der Bewegung des Kredits, von Weltmarkt als einer reelleren Distributionsform, von Luxus- und Rüstungsproduktion etc. wird hier abstrahicrt.

30) Grundrisse, S. 321 ; Revenue hier im engeren Sinn.

31) „Eine Klasse die $G-W$ durchmachte, nicht $G-W-G$. . die kaufte, ohno zu verkaufen ; MEW Bd. 26.3, S. 44: Klassen also, welche die Zirkulation des Kapitals nur, eingleisig' als Abzugskanal tangieren. 
a) Auch in der Phase günstiger Akkunulationsbedingungen, trotz möglicher Reallohnsteigerungen und sich vermehrender Arbeiterzahl, ist die produktive Arbeiterbevolkerung kein ausreichendes Tauschzentrum für das Kapital, das deshalb das Absatzfeld der Produktion zu erweitem sucht und auch in der Erweiterung des unproduktiven Konsumfonds spezifischer Mittelklassen eine Form findet, die einer Uberproduktion von Waren vorbeugen hilft.

,Die Kapitalistenklasse vom Akkumulationstrieb gepeitscht, die Unproduktiven okonomisch den blofen Konsumtionstrieb, dic Verschwendung darstellend. Und zwar dies das einzige Mitfel, der Uberproduktion 7 a entgehen, die zugleich existicrt mit einer Überbevölkerung im Verhältnis zur Produktion" (32).

b) In Phasen von Überproduktionskrisen nun, wobèi wir die Überproduktion im oben umrissenen Zusammenhang der Überakkumulation von Kapital begreifen mussen, kann der Konsumtionsfonds der produktiven Arbeiterbevökerung erst recht kein ausreichendes Tauschzentrum darstellen (fallende Tendenz der Reallöhne, Freisetzung etc.), so dał der unproduktiveKonsum dieser Klassen hier als eine Form unter anderen auftritt, die in den Ausgleich und in die Überwindung der Uberproduktionskrisen hereinspielen wird. --

An dieser Stelle muß jedoch auf die innere Formdifferenziertheit eingegangen werden, in der die unterschiedlichen Mittelklassen im Gesamtreproduktionsprozeb des Kapitals wirken. Das hier entwickelte Moment der unproduktiven Konsumtion als der Überproduktion vorbeugende und sie ausgleichende Form charakterisiert einen spezifischen Teil der Mittelklassen. Gilt etwa für die Masse der lohnabhängigen Zirkulationsarbeiter und für weite Bereiche der lohnabhängigen Dienstleistenden daßs der Preis, den sie für die Ausübung kommerzieller Funktionen und die Leistung von Diensten erhalten, sich letztlich nach nichts anderem als nach den Gesetzen richtet, die den Preis der Lohnarbeit allgemein regeln, d. h. durch die Reproduktionskosten ihrer Arbeitskraft bestimmt wird (33), so wird insbesondere den Revenuen dieser Bereiche eine Grenze gezogen sein, die diesen Revenuen keine besondere Rolle in der Ausgleichung von Überproduktionstendenzen zukommen läkt.

Andererseits wäre es falsch, diese Funktion des unproduktiven Konsums auf die ,der Bourgeoisie aggregierten Klassen“ zu beschränken, auf „Kleinkapitalisten, Kleinaktionäre, Träger von mittelbarem Vermögen etc." (34). Marx zählt in den "Theorien über den Mehrwert" neben den - im Voranschreiten der kapitalistischen Produktionsweise an Bedeutung verlierenden und in diesem Rahmen außerhalb der Untersuchung gelassenen - Grundeigentumern und deren Dienstboten „künstliche Mittel" auf, die eine der Überproduktion entgegenwirkende Nachfrage herzustellen haben:

„,Aber diese Grundrentner genügen nicht, um, an adequate demand" zu schaffen. Es nuls zu künstlichen Mitteln gegriffen werden. Diese bestehen in starken Steuern, eincr Masse Stads- und

32) ebenda, S. 42: von mir hervorgehoben

33) dazu Girundrisse, S. 371 und MEW Bd. 25, S. 303-313

34) Kommunist 4/5: Einschätzung ..., a. a. O., S. 51 
Kirchensinekuristen, grotser Armeen, Pensionen, Zehnten für die Pfaten, bedeutender Nationalschuld und von Zeit zu Zeit kostspicigen Kriegen' (35).

Ohne in diesem Rahmen den weiten und engen Aspekt im Marzschen Begriff der unproduktiven Konsumtion diskutieren zu können, onne in diesem Rahmen auf die klassenspezifischen Formen unproduktiver Konsumtion im einzelnen eingehen zu können, werden doch insbesondere die destruktiven und repressiven siatlichen Ambeitsfunktionen hervorzuheben sein, wenn dieser Typus von Konsumtion klassenspezinsch entwickelt wird. Im Gegensatz zur lohnabhängigen kommerziellen Arbeit und zu bestimmten lohnabhängigen Dienstleistungen (infrastrukturelle, allgemeinwissenschaftliche Arbeiten, privates Dienstleistungsgewerbe etc.), deren unbezahlte Mehrarbeit (auch wenn sich diese nicht in der Form des Melirwerts darstelli) zur Senkung der Zirkulationskosten oder allgemein zur Senkung der faux frais der kapitalistischen Produktion beiträgt, im Gegensatz zu unproduktiven A rbeiten, die in den Reproduktionsfonds der Produktionsagenten eingehen (Bildungs-, Gesundheitswesen etc.) etc., fällt unproduktive Konsumtion von Mehrwert also insbesondere denjenigen Klassen zu, die okonomisch nichts als den bloken Konsumtions. trieb, einzig einen Abzug von dem in seinem Kreislauf begriffenen Kapital darstellen.

2. Zeigte sich eben, wie das Wachstum des Mehrprodukts auf der Basis antagonistischer Distributionsverhältnisse die Erweiterung der unproduktiven Konsumtion und damit zugleich die Expansion spezifischer Mittelklassen notwendig macht, so stelit das Wachstum des Mehrprodukts nur einen Aspekt der sich entfaltenden Produktivkraft der Arbeit dar, die andererseits - wie wir sahen - als verminderte Nachfrage nach produktiver A rbeit und in der Umwälzung der Kapitale ais Freisetzung von Arbeit erscheint, so daß

a) qua gewachsenem Mehrprodukt eine zunehmende Verwendung von Arbeit für unproduktive Tätigkeiten möglich wird, wie sie die Fortsetzung der kapitalistischen Produktion auf erweiterter Stufenleiter erfordert. Wie einerseits die Ausdehnung der kommerziellen Arbeitsmasse der Bewegung der Geld- und Warenkapitale folgt, die dem Wachstum des produktiven Kapitals zu entsprechen haben (36), so reflektiert andererseits die kommerzielle Arbeitsmasse nicht einfach den geschwollenen Wert der ihr gegenüberstehenden Kapitale, sondern wird -- wie die produktive Arbeitsmasse auch - stofflich bestimmt durch die Masse der transagierten Produkte, damit der Buchhaltungsfunktionen, durch die Masse der Depositen, der Kreditabschlüsse etc. Hinzu kommt, daß mit erweitertem Umfang der Produktion zur Beschleunigung und Realisierung der Warenmetamorphosen neue Arten von Zirkulationsarbeit - zumal bei sich verschlechternden Realisierungsbedingungen - notwendig werden, wie sie in den Markt- und Wirtschaftsforschungsinstituten, Werbeagenturen etc. zu leisten sind. Ebenso hat der Erweiterung der kapitalistischen Stufenle iter ein verstärkter Einbezug des Staates in den Reproduktionsprozeß des Kapitals $\mathrm{zu}$ entsprechen, dessen allgemeine Akkumulationsbedingungen es zu sichem 
gilt (37). Oies impliziert immer auch die Vemehrung inproduktiver Arbeitstuk thonen in den stathohen Kontroll. und Lenkungsapparaten, in allgemenen Wissenschatsoetreb, insbesondere in den naturwissenschaftlichen Sektoren, welche die eronderliche Entwicking der Produktivkrafte mit zu gewährleisten suchen. Doch bracht uns die Ausdehnung jeweis spezifischer Klasten nicht in einzelnen zu interessieren, wichtig ist in diesem Zusammenhang vielnehr, dab

b) der Prozess der Verwendung von Arbeit für unproduktive Tatigkeiten in der zyklschen Akkumulationsbewegung zur Erscheinung gelangt (37a). So knn insbe. sondere im Stadium einer ungenügenden Verwertungsrate die mit der Herasbildung von Uberakkumulationstenderzen freigesezte Arbeit zun Teid durch unproduktive Varwendung absorbiert werden, so dak die in dieser thase erfolgende Expansion de: industriellen Reserveamee durch das Wachstum der unproduktiven Mittelklassen vemintert werden kann. Dak und wan dieser Mechanismus der A bsorption emes Teils der freigesetzten Arbeit durch unproduktive Verwendung die kapitalistische Gesellschaft nicht von Reservearmee, Arbeitslosigkeit etc. zu befreien vermag, wird sich erweisen.

Ls hiethe bbrigens diesen Prozels der Absorption von freigesetzter Arbeit sebr oberfächlich begreifen, wenn man annahme, das die freigesetzten Arbeiter unpro duktive Verwendung erfahren. Dies stell nur einen Aspekt dar. Viehneh konmt es darauf an, zu erkennen, dab die nachruckenden Arbeitsgenerationen in progressiver Proportion unproduktiv verwand werden. Der reale Verlauf dieses Prozesses, die Moditikationen, die er annimmt (Arbeitsemigration etc.) bleiben atsethab der Betrachtung.

3. Wicht selten gehen marxistische Autoren davon aus, dats die Ausweitung der unproduktiven Produktion und unproduktiven Sektoren allein auf emer gesteigerlen Mehwertproduktion des produktiven Sektors beruhe (38). Dabei geht völlig verloren, dak ein groker Teil der unproduktiven Arbeiten sich nicht allein gegen die sibgeleiteten Fomen des Mehrwerts, vielmehr auch und moglicherweise abschlieg. lich gegen den Lohn der produktiven Arbeit tauscht (39), weil die hier gementen unproduktiven Arbeitsfunktionen zur Produktion und Reproduktion der rodukti. ven Gesamtarbitskaft taugen oder ausschlieblich als solche dienen.

Wie verschleiert auch irmmer die Quelle der jeweiligen Reventien sern mag, so Gak sich durchaus der Eindruck aufherschen kann, man würde, yom Staat bezahlt",

37) Auch wan den lolgerangen, die Jachim Hirsch aus dieser fintwicklung zieht, nicht zugestimm werden kann, sei aut seinen Autsatz hingewiesen, wo dieser Aspekt entfaltet wird: J. Hirsch: Probleme einer materialistischen Staatstheorie, lirankfurt 1973

37a) "Nicht die Freisetzung durch dic Maschine, sondern durch ma mechole Verwertung bildet den Kern der Marxschen Akkumulationstheorit." H. Grossmarn: a. a. O., S. 130 f.

38) Dies warde bereits an K. H. Roth kritisiert. Ebenso R. Schmicde: Crundprobleme.... a. a. O., S. 46: "Die Ausdehnung der unproduktiven Produktion beruht also auf einer gestiegenen Mehrwertproduktion des produktiven Sektors. Nur wenn dieser in der Lage ist, das veröröterte Mehrprodukt herzustellen, um die zunehmenden unproduktiven Schichten der Geselechaft leben und arbeiten zu lassen, ist diese Ausdehrung möglich." Die $z u$ kritsierenden Implikationen dieser Bestinnung können hier nicht verfolgt wer. den.

39) dazu MEW Bo. 26.1, S. 127 
die Bewegung des produktiven Lohntonds muls als wesentliche Bestimmung der Entwicklung der modemen Mittelklassen begriffen werden. Dic immense in ihrer spezifischen Form den gesellschaftichen Bedürnissen freilich immer nachhinkende - Ausdehung des Gesundheitswesens, der arzlichen und pflegerischen Betreuung, die Vermehrung der Arbeitsfunktionen in bügerlichen Bildungsbetrieb, die gewerkschaftichen, genossenschaftichen oder politischen Apparate, die Armeen aun tem Schlachteld der offentlichen Sozialarbeit etc., all dies ist zwar nucht allem und ausschliethich dem Lohn des produktiven Gesamtarbeiters verdankt, nichtsdestoirotz blieben jene Entwicklungen unter Abstraktion von dieser Revenuequelle unprodukiver Arbeit total unbegriffen. Oder was die privaten Dienste anbelangt, so bingt die bntwicklung zunehmender Frauenarbeit und die $v$. a. damit einhergehende Freisetzung von fruher inmerhab der Familien durchgefühten Arbeiten immer die Moghichkeit in sich, auch diesen Sektor von Dienstleistungen duf der Basis der Revenuequele $\forall$ wachsen zu lassen. Wir halten also fest, dak

a) mit dem absoluten Wachstum der produktiven Arbeiterbevökerung bei beschleunigtei Akktimulation von Kapital, mit einer möglichen Erhohung der Reallohife. mit enem sich ausdehnenden Lohnfonds insgesamt auch derjenige Teil expandieren wird, der direkt oder indirekt (Steuen) zur Bezahlung unproduktiver priva ter oder offentlicher Dienste verausgabt werden kann und mub. Stellt diese Phase ein Stinulans der Expansion unproduktiver Mittelklassen dar, so wird umgekehrt

b) in Phasen unterkuhlter oder gar stagnierender Akkumulationsbewegung, bei verminkertem Wachstum oder gar rükläufiger Entwicklung der Zahl der produktiv Beschäftigten, mit einsetzendem Lohndruck etc., der Expansion von Mittelklassen eine Schranke gesetzt sein.

Obwohl die hier entwickeiten Aspekte nicht die reake Bewegung der Mit telklassen im industriellen Zyklus erklären können, letztere ist eincig in der Analyse der realen historischen Bewegung des Kapitals zu gewinnen, legen diese Aspekte doch are materielle Basis oflen, aut der sich das absolute Wachstum der neuen Mittelklassen verwirklichen kann. Es bleib dabei immer zu berucksichtigen, dals das Wachsturn der Mittelklassen nicht allein durch die innere Widerspruchlichkeit des Kapitalakkumulation bestimnt wird: mit der Verschärfung der Klassenkämpfe und der poitischen Widerspriche, mit ihr die Ausdehnung der staatlichen law-and-order Funktionen, die Ausdehnung der ideologischen Stände etc. wird der Einbezug anderer Momente des gesantgesellschaftlichen Reproduktionszusamnenhangs erforderlich, die hier aukerhab der Betrachtung bleiben.

\section{4 entgegenwibende Momente}

1. Das Wachstum unproduktiver Klassen tangiert zunächst den einen Faktor der Produkion des Mehrwerts, die Zahl der produktiven Arbeiter, indem es die Bevolkerungsressourcen emengt, aus denen sich die produktive Arbeitsmasse rekntiert. Hierbei sind im wesentlichen zwei Momente zu unterscheiden:

a) Wie bereits ausgefuhrt, erfordert die Stetigkeit des Aklumulations ozesses die Vermehrung der Bevölkerung, auch wenn umgekehrt die resetze, die d; : Wachstum

3 Probleme des Klasenhampfs 13 
der Population bestimmen, nicht losgelöst vom historischen Verlauf der kapitalistischen Akkumulation begriffen werden können. Wenn hier also das Bevölkerungswachstum als Voraussetzung der Akkumulation betrachtet wird, ist darauf Rücksicht zu nehmen, daß dieses Wachstum in den fortgeschrittenen kapitalistischen Ländern, soweit es sich aus der Relation von Geburten- und Sterbeziffern ergibt, im Vergleich zu den hohen Zuwachsraten des 19. Jahrhunderts durch eine allgemeine, säkulare Rückläufigkeit charakterisiert wird, wobei wir von nationalen Besonderheiten und zeitweilig gegenläufigen Tendenzen (Nachkriegsgenerationen z. B.) abstrahieren. Henryk Grossmann versuchte nachzuweisen, daß von einem Mangel an A rbeitsbevölkerung in kapitalistischen Metropolen eigentlich nur während der industriellen Revolution keine Rede sein konnte, daß der in dieser Periode sich angesammelte Überschuß an Bevölkerung mit dem Voranpreschen der Akkumulation von Kapital mehr und mehr abgebaut wurde und ein Bevölkerungsüberschuß in den heutigen kapitalistischen Nationen nahezu ausschließlich auf der Grundlage sich herausbildender Überakkumulationstendenzen entstehen kann (40).

b) Die Reproduktion des Kapitalverhältnisses auf erweiterter Stufenleiter heißt zugleich, zunehmend vorkapitalistische Sphären der Gesellschaft (überkommene handwerkliche, agrarische Strukturen etc.) in den ReproduktionsprozeB des Kapitals, in seine Verwertungsbasis einbezogen zu haben. Einerseits sind diese Sphären innerhalb der kapitalistischen Länder im Verlauf der herrschenden Produktionsweise weitgehend aufgesogen worden (41), andererseits ist die Ausdehnung des Kapitalverhältnisses aus den großen Industrienationen heraus ebenfalls nicht unbegrenzt möglich (Übergangsgesellschaften; soziale, politische und ökonomische Schranken der Einbeziehung nicht- oder allein halb-industrialisierter Länder etc.), worauf aber in diesem Rahmen nicht eingegangen werden muß.

Aliein diese beiden Faktoren, rückläufige, natürliche' Zuwachsraten einerseits und weitgehende Absorption vorkapitalistischer Sphären andererseits, obwohl ihnen durch Arbeitsemigration oder Wanderungsbewegungen entgegengewirkt werden kann, zeigen, da\} -- vom Standpunkt der Mehrwertproduktion aus betrachtet - das Kapital der Expansion der Mittelklassen als einer zusätzlichen Einengung seiner Verwertungsbasis, einer zusätzlichen Einengung der potentiellen produktiven Arbeitsrnasse, durchaus nicht gleichgültig gegenüberstehen kann, die Ausdehnung der Mittelklassen darum in Grenzen gehalten werden muß, die das für die beschleunigte Kapitalakkumulation erforderliche Wachstum der Zahl der produktiven Arbeiter Zu gewähren trachten.

Wenn also gesagt wurde, daf die periodisch freigesetzte Arbeit zu einem Teil unproduktive Verwendung findet und die periodische Ausdehnung der industriellen Reservearmee durch die Expansion der Mittelklassen vermindert werden kann, so klärt sich nun, warum dieser Mechanismus nur begrenzt funktionieren kann. Dies insofern, als die Bildung der industriellen Reservearmee sich nicht allein als Resultat der Widersprüchlichkeit der Kapitalakkumulation darstellt, sondern ihre Existenz wird zugleich zur Voraussetzung und unumgänglichen Bedingung der Akkumulation:

40) H. Grossmann: Der Akkumulations ..., a. a. O., S. $373 \mathrm{ff}$.

41) dazu E. Cirünberg: Der Mittelstand in der kapitalistischen Gesellschaft, Leipzig 1952 
"Wenn aber eine Surplusarbeiterpopulation notwendiges Produkt der Akkumulation oder der Entwicklung des Reichtums auf kapitalistischer crundlage ist, wird dicse Überbevölkerung umgekehrt zum Hebel der kapitalistischen Akkumulation, ja zu ciner lxistenzbedingung der kapitalistischen Produktionsweise." Sie schafft für die wechselnden Verwertungsbedürnisse des Kapitals „das stets bereite exploitable Menschenmaterial, unabhängig von den Schranken der wirklichen Bevolkerungszunahme" (42).

Die notwendige Disponibilität von Arbeitskräften zur produktiven, mehrwertproduzierenden Verwendung für die nach Krise und Depression erfolgende Produktion auf erweiterter Stufenleiter erscheint als Grenze der Absorption freigesetzter Arbeit durch unproduktive Verwendung, erscheint als Begrenzung der Mittelklassen. Wird diese Grenze überschritten, reicht so die Kontraktion der Reservearmee in der Belebungs- und Aufschwungsphase der Akkumulation zu deren beschleunigter Fortsetzung nicht mehr aus, so können, wenn andere Faktoren (zusätzliche A rbeitsemigration, Bevölkerungswachstum etc. einerseits und Steigerung der Mehrwertrate andererseits) nicht ausreichend eingreifen, diverse Bereiche der Mittelklassen selbst kontrahiert werden. Doch kommt es hier wiederum darauf an, zu erkennen, dał nicht allein unproduktive Arbeiter in produktive Arbeiter verwandelt werden können, vielmehr wandelt sich das Teilungsverhältnis der nachrückenden Arbeitsgenerationen in dieser Phase zugunsten der produktiven Verwendung, zuungunsten der unproduktiven Verwendung.

Jacob Morris, der im Anschlur an die Untersuchungen Gillmans das Verhältnis von Arbeitslosigkeit und unproduktiver Arbeit analysiert, bleibt die Einsicht in die Grenzen der Absorption freigesetzter Arbeit durch unproduktive Verwendung notwendig verschlossen, da er - wie Gillman - von einer

,anhaltenden Kluft zwischen der Fähigkeit des Monopolkapitalismus zur Schafrung potenticllen Mehrwerts und der Iähigkeit, dieses Potential tatsächlich zu realisieren" "(43)

ausgeht, also die Bewegung der unproduktiven Arbeitsmasse auf dem Boden der Unterkonsumtionstheorie entwickeln will. Wenn er folglich konstatiert, daß ,unproduktive Arbeit ein Ersatz für Arbeitslosigkeit" sei(44), so bleibt die Frage, inwieweit, bis an welche Grenzen heran freigesetzte Arbeit unproduktiv verwandt werden kann, auf dem Boden derartiger Konzeptionen notwendig unbeantwortet. Weder die notwendige Disponibilität von potentiellen Arbeitskräften, noch eine durch die beschleunigte Akkumulation begrenzte unproduktive Verwendung von Mehrtwert (siehe 2) wird diesem akkumulationstheoretischen Ansatz zum Problem. Dieser Mechanismus: unproduktive Arbeit als - insbesondere staatlich vermittelter - Ersatz für Arbeitslosigkeit, vermag die kapitalistische Gesellschaft weder von Arbeitslosigkeit noch von den anderen historisch-spezifischen Existenzformen der relativen Überbevölkerung zu befreien. Dies um so weniger, je enger sich die Erfordernisse der Akkumulation als Schranken um die staatlich verfugbaren Ressourcen

43) J. Morris: Arbeitslosigkeit und unproduktive Arbeit, in: Kapitalismus und Krise (Hrsg. C. Rolshausen), lirankfurt 1970 , S. 85 
$\operatorname{legen}(44 b)$.

Neben der Funktion der industrielien Reservearnee, für die emeute bescher. nigte Akkumulation von Kapital ein disponibles Reservoir an Arbeitskraften bereit. zuhalten, stell ihre gleichzeitige Aufgabe als Regulator der Lohbewegung (45) eine Grenze für die unproduktive Verwendung von freigesetzter Arbeit dar. Den - fiktiven .... Fall gesetzt, dak die industrielle Reservearmee weitgehend durch die unprodukitue Verwendung von A rbeit ersetzt wirde, wäre diese Regulatorfunk. tion tendenziell aufgehoben. Der fü die Uberwindung der Verwertungsschwierigketen notwendige Lohndruck, die Senkung der Reallohne, wirde weitgehend aufgehoben (46).

2. Obwohl die unproduktive Konsumtion von spezifischen Mitelklassen die Uberproduktion von Waren verhindern oder ausgleichen hilft, stellt der Konsumtions. fonds der gusamten Mittelklassen eine Vermindenung der kapitalisierbaren Mehr. wertmassen dar, so dał die zur Fortsetzung der Akkumulation notwendige (Minimal-) Grohe der Mehrwertmasse neben den beschriebenen Faktoren (erschwert zu steigernde Mehrwertrate, reduziertes Wachstum der Zahl der produktiven Arbeiter etc.) auch durch den vermehrten Konsum der sich ausdehneriden Mithelklassen bedroht wird. Selbst wenn diese Minimalgröke nicht bedroht ist, werden die auch durch den Mittelklassenkonsum erweiterten toten Kosten der kapitalistischen Produktion auf die beschleunigte Kapitalakkumulation abflachend einwirken, werden die Verwertungsbedingungen des Kapials geschmälert.

Auch dieser Aspekt zeigt, dak vom öknomischen Standpunkt aus dem Kapital daran liegen mus. die Expansion der Mittelklassen in Grenzen zu halten. Wenngleich dem industriellen Arbeitsprozek weit nachhinkend, bewirken die technologischen und arbeitsmethodischen Umwälzungen auch der kommeriellen und Dienstleistungsprozesse und ihre damit einhergehende Ehohung der techischen Zusammensetzung zum einen cine Wachstumsveminderung der unprodukiven Gesantarbeitskraft, zum anderen wird es auf dieser Basis mit de Veralgemeinerung der Lohnarbeit moglich, qualifizierte kommerziele und Dienstleistungsarbeiten tendenziell auf einfache Durchschnitsarbeiten zu reduzieren, so dals einhergehend mit der Steigenung der allgemeinen Arbeitsproduktivitat die Reproduktonskosten bieser Arbeitskräfte gesenkt werden können, die Konsumtionskraft dieser Klassen reduziert wird. Wie immer sich diese Prozesse im realen Verlauf der herischenden Produktionsweise durchseben, hier soll allein einsehbar werden: je umfangreicher die modemen Mittelkiassen im Gesamtreproduktionsprozeß des Kapitals agieren, um so entscheiciender wird es das Kapital, diese gesellschaftichen Spharen an dia Zigel zu rehmen, um so nehr woren diese Klassen den Zwängen der kapialistischen Akkumulation unterworfen sein. Arbeitslosigkeit und Arbeitshetze, Min-und Mer. schleudern der Individuen von einer Funktion zur anderen, bomierte Detailarbe ten, Unterordnung in die Befehlsherarchie, zunehmende Auspressung von Mehrabeit ... gestern noch als Puffer zwischen den antagonistischen Fronten von Lohnar-

44b) siche dazu M. Cogoy: Wertthorie ..., a. a. O.

45) dazu MEW Ba. 23, S. 666

46) Dieser Aspekt kann jedoch nicht losgeböt von den anderen Mechanismen der Lohnbewegung (gewerkschaftlicher Kampt otc) diskutiort werden. 
beit und Kapital beklatscht, werden diese $Z$ wänge den Weg weisen, auf welcher Seite zukmplenist.

\section{5 relatives Wachstum der Mithelklassen--zum Verhalmis von produktiver Arbeireklasse und Mitrelklassen in Verlauf der Akkumulation}

Uer im Verouf der Kaphalistischen Produktionsweise und aut erweiterter Stufenleiter der Produktion notwendigen Expansion der modernen Mittelklassen, der die Entfaltung der gesellschaftlichen Produktivkraft der Arbeit in der Form der Akkumulation von Kapital die materielle Basis sichent, ist folglich -... wie wir oben sahen .. Gurch Erfordemisse eben dieser Akkumulation eine Grenze gezogen: die Bewegung der Mittelkissen erscheint als Ausdruck der inneren Widersprüchlichkeit der kapitalistischen Akkumblation. ,Das Kapital ist selbst der prozessierende Widerspruch (dadurch), dak es die Arbeitszeit auf ein Minimum zu reduzieren stört" so auch die unprotuktive gesellschaftiche Arbeitszeit zur Ausdehnung bringen will, "Wahrend es andererseits die A rbeitszeit als einziges Mak und Quelle des Reichtums $5 e t z t^{\circ}(47)$ und hier als Begrenzung der unproduktiven Verwendung gesellschaftliwher Arbeitszeit wirkt. Die beschränkenden und anstachelnden Einwirkungen der Akkumulation auf die Expansion der Mitelklassen und deren Vertältnis zum Wachstum der produktiven Arbeiterbevolkerung (wir betrachten also nun das relative Wachstum der Mittelklassen), obwohl sie fortlaufende und stetig wirksame Faktoten darstellen, werden periodisch an Stärke und Umfang gewinnen.

Der Pegriff der Periodizitä neint wiederum die bereits angesprochenen zwei Aspekte, den industriellen $Z y k l u s$ und zum anderen die weiter gefalsten historischen Phasen der Akkumulation, Phasen, innerhalb derer die Steigerung der durchschnittichen Arbeitsproduk tivität nicht uber ein relativ (!) konstantes Niveau hinaustreibt, oder anders ausgedricki, innerhalb derer die Entwicklung der organischen Zusammensekzung als Reflex eines qualitativ verhältnismälig (!) unverändert bleibenden industriellen Arbeitsprozesses keine gravierenden Sprünge aufweist, wie sie etwa den Ubergang zur Produktion unter monopolistischen Prämissen gegen Ende des 19. Jahrhuderts oder die industiellen Umwälzungsprozesse während und im Gefolge des II. Weltkriegs charakterisieren. Ohne auf die Vermittlung beider Aspekte eingehen zu können -- eine solche Arbeit steht noch aus --, kann festgehalten werden, dafs mit der Vollendung der historischen Phasen der Akkumulation deren zyklische Bewegungen makanter werden, eine erneute beschleunigte Akkumulation - wie wir sahen auch auf Grund der vorangeschrittenen Expansion der Mittelklassen -.. immer schwieriger zu bewirken ist, so daß die Kapitalakkumulation in eine Stagnationsphase zu geraten droht (48).

1. So werden in Zeiten beschleunigter Kapitalakkumulation die eine relative Expansion der Mittelkasen begrenzenden (d. h. nicht unbedingt aufhebenden, Fakto ren verstärkt whken können, da

47) Grundrise, S. 593

48) dazu Gillman: Das Gesetz. .., a. a. O., S. 143 f,; scine Interpretation der hier konstatierten cmpirischen Daten wird aus den oben angefürten Gründen abgeichnt. 
a) das nun notwendige Wachstum der produktiven Arbeitsmasse die unproduktive Verwendung von $A$ rbeit einschränken mub und

b) die für die beschleunigte Akkumulation erforderliche Größe des kapitalisierbaren Mehrwerts das Wachstum des unproduktiv verwandten Mehrwertfonds (faux frais allgemein) zu reduzieren sucht.

Beide Momente, Akkumulationsrate und Wachstum der produktiven Klasse, schliethen selbstverständlich nicht das absolute Wachstum der neuen Mittelklassen aus, im Gegenteil, dieses wird

c) mit der erweiterten Stufenleiter der Produktion (Ausciehnung der kommerziellen Arbeitsfunktionen, Ausdehnung von unproduktiven Arbeitsfunktionen zur Aufrechterhaitung der allgemeinen Akkumula tionsbedingungen etc.) notwendig und

d) durch die Vergrößerung des Mehrprodukts sowie das Wachstum des Lohns der produktiven Gesamtarbeitskraft möglich.

2. Umgekehrt werden in Zeiten einer (relativ bis absolut) stagnierenden Kapitalakkumulation jene die relative Expansion der Mittelklassen anstachelnden Momente verstärkt wirken können, da

a) die freigesetzte Arbeit vermehrt unproduktive Verwendung finden kann und

b) die Überakkumulation von Kapital (damit auch die Überproduktion von Waren),

d. h. die nun nicht in produktiv anlegbaren Größen produzierte Mehrwertmasse, eine (in Bezug auf die gesamte Mehrwertmasse relative) Erweiterung des unproduktiv verwandten Mehrwertfonds möglich macht.

Beide Momente, sinkende Akkumulationsrate und reduziertes bis rückläufiges Wachstum der produktiven Klasse, schließen wiederum nicht einen absoluten Rückgang der unproduktiv arbeitenden Bevölkerung aus:

c) einerseits durch den stagnierenden bis eingeengten Produktionsumfang (Freisetzung von Zirkulationsarbeit etc.),

d) andererseits durch ein stagnierendes oder gar schrumpfendes Mehrprodukt und die Kontraktion des produktiven Gesamtlohns

kann die absolute Ausdehnung der Mittelklassen unterbunden werden.

Wiederum muß betont werden, dak die hier umrissenen Bestimmungen, welche die bislang isoliert betrachteten Momente auf dem Hintergrund der unterschiedlichen Entwicklung der Akkumulation zusammenfassen, nicht die reale Bewegung der Mittelklassen im historischen Prozek kapitalistischer Akkumulation erklären können, vielmehr haben wir es hier mit allgemeinen Bestimmungen zu tun, die unter Einwirkung besonderer ökonomischer, politischer und ideologischer Formen, also allein in modifizierter Weise zur Erscheinung gelangen. Sie dienen allein als kategoriale Grundlage zur Entschlüsselung jeweils spezifischer Phänomene. Die allenthalben konstatierte Tatsache etwa, daß der unproduktiv arbeitende Bevökerungsteil in geringerem Maße als der produktiv arbeitende Bevölkerungsteil dem zyklischen Gang der Akkumulation unterworfen ist (49), wird hier begreifbar, da das relative Wachstum der Mittelklassen selbst in der Phase eines kritischen Akkumulationsverlaufs aufrechterhalten werden kann. Diese Bewegung soll an einem empirischen Exkurs verdeutlicht (!) werden.

49) Etwa Schmierer: Die neuen Mittelklassen..., a. a. O., S. 53 oder Semmler/Hof fmann: Kapitálakkumulation . . , a. a. O., S. 36 
Exkurs:

Die von Gillman für die Untersuchung des tendenziellen Falls der Profitrate gewonnenen Erhebungen beziehen sich auf die verarbeitende Industrie der Vereinigten Staaten von 1919 bis 1939, geben daher nur einen Einblick in die Bewegung einer Klasse von Zirkulationsarbeitern. Etwa die Zirkulationsarbeit in Geld- oder Warenhandlungskapital oder die unproduktive Arbeit im öffentlichen Dienst bleibt unberücksichtigt, doch würde eine Untersuchung dieser beiden Bereiche die hier konstatierbare Tendenz des ausgeprägteren relativen Wachstums der Mittelklassen in den kritischen Stadien der Kapitalakkumulation im Vergleich zu den Stadien einer beschleunigten Kapitalakkumulation nicht vemeinen, sondern eher bestärken: etwa die unproduktive Arbeit im öffentlichen Dienst ist viel weitgehender vom zyklischen Gang der Kapitalakkumulation abgeschirmt (z.B. durch Beamtenstatus), als die hier beobachtete Fraktion der Zirkulationsarbeiter.

1. Spalte (5) verdeutlicht, wie in Zeiten einer flüssigen Akkumulationsbewegung (z.B. 1926-1929) das Wachstum der faux frais zugunsten der kapitalisierbaren Mehrwertmasse (annähernd $\mathrm{m}-\mathrm{u}$ ) reduziert werden muß, obwohl die toten Kosten absolut ansteigen, verdeutlicht weiterhin

2. daf umgekehrt, in Zeiten einer stagnierenden Akkumulation (z.B. 1930-1932) das Verhältnis von produzierter Mehrwertmasse, damit auch das Verhältnis des kapitalisierbaren Mehrwerts zu den toten Kosten zugunstea der letztgenannten verschoben werden kann, obwohl die absolute Größe der faux frais mit dem abnehmenden Mehrprodukt fällt.

3. Spalte (7) zeigt, wie in den Zeiten einer stagnierenden Kapitalakkumulation (ab 1921; ab 1930) die faux frais relativ zum Lohnfonds der produktiven Arbeiter rapide ansteigen, obwohl beide Gröfen absolut fallen. Diese Relation kann aber, da die faux frais nicht allein den Lohnfonds der in diesem industriellen Bereich präsenten Zirkulationsarbeiter umfassen (siehe Anmerk zu Spalte (4)), nicht die relative Entwicklung der Zahl der Zirkulationsarbeiter offenlegen.

4. Dazu ist die in Spalte (9) gezogene Relation aufzugreifen. Zuvor muß aber vermerkt werden, (a) daß in Spalte (8) auch die Gehälter der technischen (also oft produktiven) Angestellten aufgeführt sind, und (b) daf die Gehältei der Angestellten auch in den Jahren der Depression über den Löhnen der produktiven Arbeiter lagen (49a), so daß die nun zu definierende Tendenz in der Tabelle überzeichnet zum Ausdruck kommt:

49a) dazu Gillman: Das Gesetz . . . . a. a. O., S. 110 


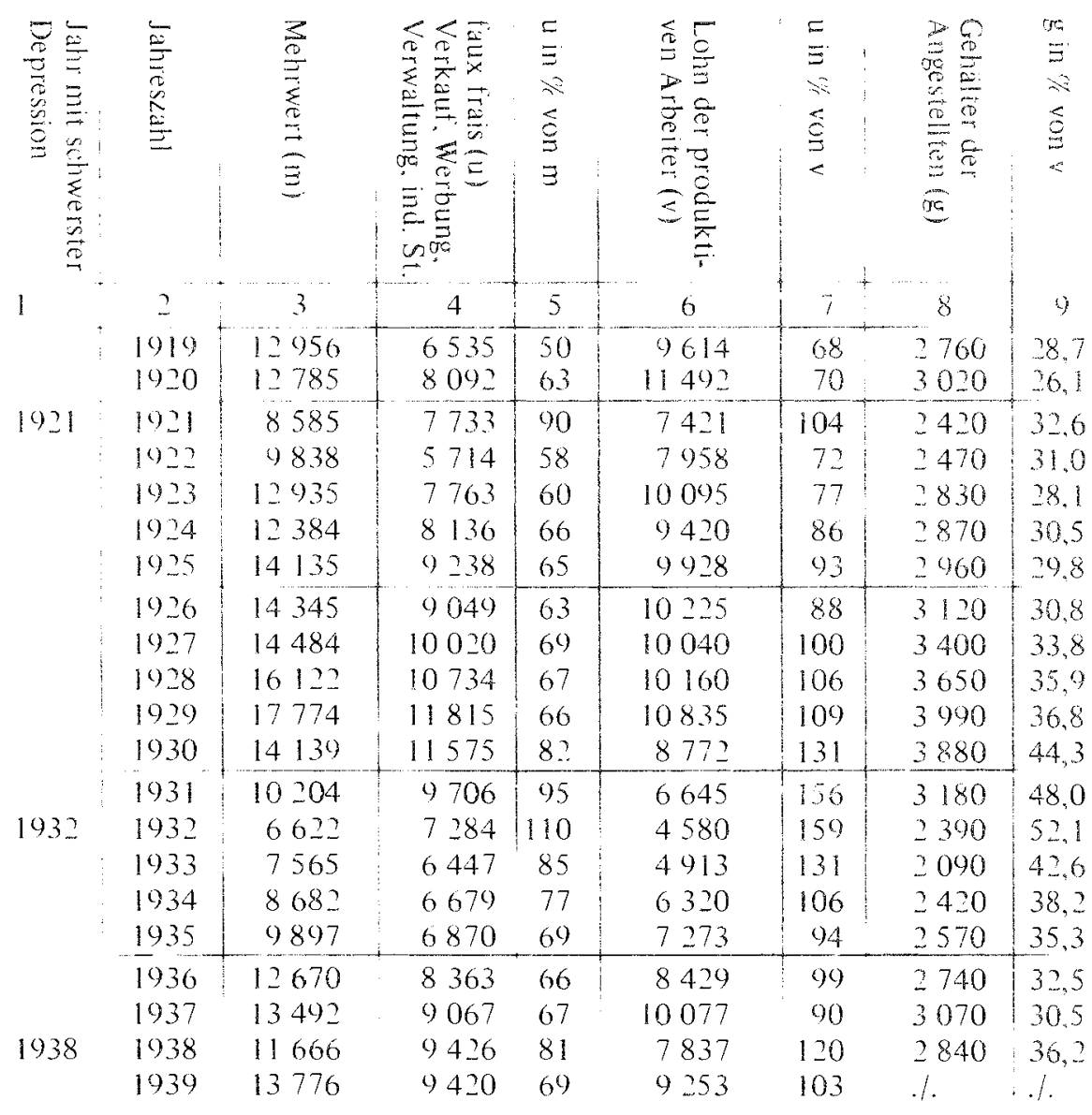

a) verarbeitende Industrie der USA 1919-1939

b) absolute Angaben: Dollarbeträge in Millionen

c) Quelle: Gillman, ,Das Gesetz...", a. a. O., S. 124 f. und 110

d) Spatte (8) ist errechnet

Obwohl der Lohnfonds der Angestellten in den Jahren der Depression ( $z$. B. 1930-1933) wie auch der Lohnfonds der produktiven Arbeiter absolut fallt, stellt er verglichen mit letzterem eine relativ wachsende Gröke dar, d. h. selbst die diesem produktiven Kapital gegenüberstehenden Zirkulationsarbeiter, ob. wohl auch sie der zyklischen Abwärtsbewegung unterworfen sind, sind in einem geringerem Maßse dem Zyklus unterworfen und werden in geringerem Malie als die produktiven Arbeiter freigese tzt.

Fazit: Der oben entwickelte Zusammenhang, daf jene die relative Expansion des Mittelklassen begrenzenden Faktoren in Zeiten einer beschleunig ten Akkumulation 
von Kapital stärker zur Wirkung gelangen als in Stadien emer schleppenden, stagnierenden Akkumulation. findet sich in diesem (zugestandenemaken engen) Beispiel bestätigt. Wem man es aber dadurch erweiterte, indem man die enhohten Verteidigungs ausgaben in der (relativen bis absoluten) Stagnationsphase des amen. kanischen Kapitals yon 1930 bis 1938 , die u. a. ene Erhohung der als Militar fungierenden unproduktiven Personenzahl bedeuten (49b), oder de von der zyklischen Akkumulationsbewegung relutiv (1) unbetroffenen Beschäfigten im orfenth chen Dienst cinbezoge, wurde diese Tenden ausgeprggter erscheinen.

\subsection{Zusamentiastang}

Wir gingen zi Anfong dieses Autsatzes von der Frge aus. welche Bedeutung die Marxsche Kategone der Mitelklassen im Kontext ene! materialistischen Klassentheorie erlangt, ob dieser Begriff als ein Ausgangspunkt zur Analyse realer Klassenverhaltnisse und Kassenkampre dienen kann. Weit davon entem, alle Aspekte de marxistischen Khssentheorie entwickelt zu haben, so mukte die Analyse der inneren Formdifferenziertheit der produktiven und unproduktiven Klassen weitgehend aukerhab der Betrachtung bleiben, ebenso die Analyse der realen gesellschaftichen Arbeitsprozesse, die Analyse der Bewegung des Grundeigentums ind der Kapitalistenklasse elc., konnte dennoch dargestellt werden, inwiefern die Marxschen Ansführungen über die relative Abnahme des Proletariats und die relative Zunahme der classe moyeme durchaus die Klassenstrukturen der bürgerhchen Gesellschaft zu begreifen erlabben, wern wir die Produktion und Reproduktion diescr Klasserstrukturen im Nachvollzug der Bewegungen des Werts in der Form kapitalistischer Akkumulation entwickeln. Ausgehend von den spezifischen Bedingungen der Vermehrung der produktiven Klasse hin zu denjenigen Momenten, die uns das Wachstum der modemen Mittelklassen begreifen lassen, sahen wir, wie sich diese von Marx umrissenen Klassenstrukturen auf dem Boden der inneren Widersprüchlichkeit des Akkumulationsprozesses he rausbilden, im Fortschrit der herrschenden Produktionsweise zunehmend an Manifestanz gewinnen und als kategoriale Grundagen in der materialistischen Analyse der realen Klassenverhälnisse und Klassenkämpfe denen.

Auch wenn in Verlauf des Aufsatzes allgemeine Bestimmungen uber die Ent wicklung der Mittelklassen zu gewinnen versucht wurde, so muß nochmals dem sich auf dieser Ebene möglicherweise aufherrschenden Eindruck entgegnet werden, die Mittelklassen stellen eir einheitliches Ganzes irn Klassengefüge der bürgerlichen Gesellschaft dar. Trotz der eingeschänkten Fragestellung sahen wir bereits, wie die imere Fomdifferenziertheit der Mittelklassen einzubeziehen war, wenn es galt, die materielle Basis ihres Wachstums zu entschlisseln. Einerseits spezifische Mittelklassen als klassenmäliger Ausduck unproduktiver Konsumtion, andererseits Klassen, die keineswegs in dieser Fom die Uberproduktionstendenzen des Kapitals angieren, zum einen Kaissen, die ihre Revenuen aus dem Lohn der produk tiven Gesamt$49 \mathrm{bi}$

ders.: Prosperitat ..., a. a. O., S. 120 
arbeitskraft ableiten, zum anderen Klassen, deren Revenuen direkt der Bewegung des Mehrwerts unterliegen etc. Schon auf der in diesem Rahmen diskutierten Ebene narxistischer Klassentheorie erweist sich, daß die Mittelklassen in der Klassenstruktur der bürgerlichen Gesellschaft und in den Reproduktionszusammenhängen auf der Ebene des Gesamtkapitals zwar ihrer ökonomischen Bestimmtheit nach einheitlich von den Bewegungen der produktiven Klasse abzugrenzen sind, die Art und Weise, die Form, in der sie dem Gesamtreproduktionsprozeß des Kapitals einverleibt diesen beeinflussen und umgekehrt von diesem beeinflußt werden, aber von Unterschied ist.

Um die bisherigen Ausführung zu verdeutlichen, wird kurz auf drei unterschiedliche Ansätze eingegangen, in denen die Herausbildung der modernen Mittelklassen besondere Bedeutung erlangt.

\section{Claus Offe}

Die systemtheoretisch und funktionalistisch beeinflußte politische Krisentheorie, wie sie sich bei Claus Offe darstellt, geht davon aus, daß in den fortgeschrittenen kapitalistischen Metropolen nicht die inneren Widersprüche kapitalistischer Akkumulation, sondern die zunehmenden Ergänzungsdiskrepanzen zwischen ökonomischen und politischen Prozessen und die in sich widersprüchliche Bewegungsgesetzlichkeit der politischen Prozesse (Rationalitätsbarrieren, Legitimationserfordernisse etc.) als Zentrum der sich krisenförmig zuspitzenden Widersprüche ,spätkapitalistischer Systeme" begriffen werden müssen:

„Nicht die ,Verwertungsschwicrigkeiten des Kapitals" selbst, sondern die Blockierung ihrer (nur noch in politisch-administrativen Formen möglichen) Sicherstellung durch ,Legitimationsdefizite" mülsten demnach heute zum Ausgangspunkt einer (nicht mehr nur ,ökonomischen", sondern politischen) Krisent heorie gemacht werden" (50).

Ohne uns auf den Begründungszusammenhang dieser Konzeption insgesamt zu konzentrieren, betrachten wir hier allein die klassentheoretischen Implikationen politischer Krisentheorie, wie sie sich auch bei Offe zwangsläufig einstellen: die Herausbildung der Klassen der bürgerlichen Gesellschaft wird nicht auf der Grundlage kapitalistischer Akkumulation, sondern verkürzt als Reflex politischer Prozesse begriffen. Nicht allein, aber auch die herrschenden Klassenstrukturen haben ihm Rahmen dieser Konzeption zu beweisen, daß ihre Genese nicht länger ausgehend von der Marxschen Kritik der politischen Ökonomie zu entschlüsseln ist. Offe spricht von ,systemfremden Resultaten einer systeminternen Bewegung“", von ,entgegengesetzten Formprinzipien“, von ,aus der Warenform herausgefallenen" Strukturen etc., die, wenn auch im ,klassischen" Kapitalismus angelegt und vorhanden, doch eine qualitative Differenz zun Verlauf der fortgeschrittenen kapitalistischen Gesellschaft konstituieren. Offe greift dabei in zweifacher Hinsicht auf klassenspezifische Prozesse-zurück: (a) einmal will er nachweisen, daß Klassenstrukturen zunehmend durch politische Prozesse und weniger durch ökonomische Prozesse bestimmt werso) C.Offe: Strukturprobleme ..., a. a. O., S. $51 \mathrm{f}$. 
den; (b) zum anderen behauptet er, die heutigen Klassenauseinandersetzungen würden weniger denn je vom Antagonismus von Lohnarbeit und Kapital geprägt.

a) Offe führt aus, daß in ,spätkapitalistischen Systemen" nicht mehr die ökonomischen, vielmehr die politisch-staatlichen Vergesellschaftungsformen die ,dominanten" seien. Wenn wir also bislang in diesem Aufsatz die Herausbildung der modernen Klassen aus den Widersprüchen des spezifisch-ökonomischen Prozesses dieser Gesellschaftsformation, des Akkumulationsprozesses, betrachteten, so müßte man - Offe folgend - bestreiten, daß die Klassenstrukturen heutiger Gesellschaft in dieser Weise entschlüsselt werden können. Er schreibt:

„Fin Blick in dic U.S.-amerikanische Arbeitsstatistik zeigt, dats der Vergesellschaftungsmodus der wirtschaftlichen Verwendung von Arbeitskraft bei weitem micht mehr als der dominante angesehen werien kann." Nach einer Unterscheidung in mehrere Sparten von Bevölkerungs. schichten fahrt er fort: "Die verbleibenden $20.7 \%$ der A ktivbevölkerung sind durch nicht-wirtschaftliche, unmittelbar politisch-staatliche Vergesellschaftungsformen bestimmt: ihre matericllen Lebensumstande und ihre Lebensperspektiven sind durch den Status als Schüler, Student, Arbeitsloser, Wohlfahrtsempfänger, Insasse von Gefängnissen oder sonstigen Anstalten, Armeeangchörige, Pensionär definiert" $(51)$.

Ohne die Aufzählung ,ökonomisch funktionsloser Schichten" hier zu beenden (Hausfrauen, Subproletariat etc.), kann resümiert werden, daß sich für Offe insbesondere das Wachstum von spezifischen unproduktiven Klassen und Schichten polizischen Prozessen (,politisch-administrativ vermittelte Statuszuteilung “) verdankt, mit zunehmendem Wachstum dieser Bevölkerungsteile also auch der ,politische Vergesellschaftungsmodus" mit der Zeit zum dominanten werden mußte.

Unterstellen wir einmal die Unterscheidung in politische und okonomische Vergesellschaftungsformen als trifftig (die systemtieoretischen Sackgassen dieser Unterscheidung gehen uns hier nichts an), so erwiese sich Offes These vom Übergang der Dominanz von der einen zur anderen dieser Formen im Verlauf der kapitalistischen Gesellschaft als falsch, denn es konnte in den vergangenen Ausführungen gezeigt werden, wie die relative Expansion dieser Bevolkerungsteile notwendiges Implikat der herrschenden Produktionsweise von Beginn an war; mit anderen Worten: der gesamte Verlauf dieser Gesellschaftsformation wäre dadurch charakterisiert, daß der ,öonomische Vergesellschaftungsmodus" nie der dominante hätte sein können. Doch sahen wir bereits, wie die Herausbildung der diversen unproduktiven Klassen ebenfalis allein ausgehend von den okonomischen Widerspruchen des Akkumulationsprozesses begriffen werden kann, daß keine Rede davon sein kann, diese Schichten hätten keine ökonomische Funktion im Reproduktionsprozeß des Kapitals. Sicherlich verdankt sich die Herausbildung dieser Klassen auch den politischen, staatlichen, ideologischen Funktionen etc., die sie zu erfüllen haben. Es charakterisiert jedoch Offe und die politische Krisentheorie allgemein, daß von den öknomischen Funktionen und Mechanismen klassenstruktureller Entwicklungen abstrahiert wird und man allein diese reelleren Funktionen aufgreift, anstatt zu sehen, dak es gilt, die unterschiedlichen Funktionsebenen als vermittelte zu begreifen. Dort, wo vermittelnde und intervenierende Momente (Statuszuweisung, Klas-

51) ders.: a. a. O., S. 41 f.; von inir hervorgehoben 
senkampformen, Studentenrebellion etc.) hineinspielen, also dort, wo sich die Bewegung der Klassen und Schichten der burgerlichen Gesellschaft nicht unmitielbar als Reflex von Akkumulationsbewegungen begreifen läßt (diese Unmittelbarkeit wäre allein bei der produktiven A rbeit oder der Zirkulationsarbeit weitgehend gegeben). schlägt Offe jenen spezifischen Marxschen $G$ ang der Abstraktion erst gar nicht ein, der allein die ökonomische Bedeutung dieser klassenstrukturellen Phänomene hatte zum Begriff bringen können. Dort, wo die materielle, ökonomische Basis der Klassenstrukturen ignoriert wird, kann sich dann der blanke Empirismus entfaiten, dem "en Blick in die Statistik" genugt, die ganze Scheike zu durchschauen.

b) Wir sahen im Verlauf der Darstellung, wie mit fortscheitender Stufenleiter der Produktion die Expansion kommerzieller A rbeiten und die von Dicnstleisiungstätig. keiten notwendig und möglich wirả, wobei ein immer größere Teil dieser Arbeiten die Form der Lohnarbeit annemen muls. Ofe interpretiert diesen Frozes folgen demaken:

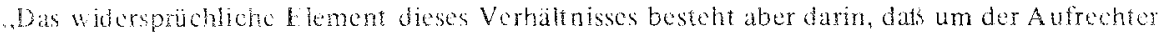

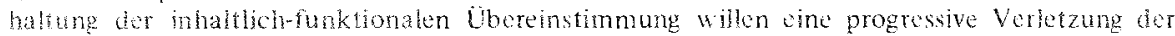
l. orm, nemlich der Warentorm, erforderlich wird: immer groblere Teile der A rbeitskraft fallen in jone konkreten Bestimmungen zurük, aus der sie die kapitalistische l' reisepung der , freien Lohbarbeit" herausgenommen hatte. Dieser subversive Vorgang cimer funk tional erforderlichen formverletzung führ nicht nur zur Verbreiterung jencs gesellschaftichen Zwischenschishton, die zwar "lohnabhangig", aber nicht "mehrwertprobukiv" sind: sie führt därber hinaus zu emer Frosion jenes legitimatorischen Grund schemas des Äquivalententauschs."

Die Austehnung der unproduktiven Sphare der Lohnarbeit stelle also eine ,progressive Verletzung der Warenform" dar, er redet von einer "fortschreitenden Ergärizung und Ersetzung abstrakter durch konkrete Abeit". Die inhaltich-konkrete Arbeit gewinne zunehmend an Bedeutung, eine ,zunehmende Identifikation des Arbeitenden mit der Arbeitsaufgabe" sei die Folge. Der Arbeitende stohe dem Resultat seiner Arbeit nicht mehr gleichgültig gegenüber, wachsende Anforderungen würden an seine Qualifikation gestellt, kurzum, die Akrualisienung inhalthicher Konflikte schreite voran.

\footnotetext{
Ait heser unasweichlichen Verschiebung des Steuerungsmediums, nit der Verlagerung der Entwicklungsdynanik aus der Sphäre des Tausches in die Sphäre der Entscheidung, wirl ter Bestand des kapitalistischen Systems von der Bewaltigung eines ateut Problems abhangig: des Problems nämlich, wio die systenfromde form daran gehindert worden kann, zum Vehikel ystemfremder Inhalte zu werden. Oder genauer: Wie die konkrete Arbeit weiterhin darauf festgelegt werden kann, sich inhaltich durch die Verwertung sbedüfnisse des Kapitals programmicren und sich ihe Entscheidungspramissen von diesen vorgeben zu lassen" (52).
}

Keine Frage, inhaltliche, das heils $t$ hier: iber die konkrete Gestalt der A rbeit vermittelte Konflikte gehen in den Konstitutionsprozeß der realen Klassenkämpfe ein, doch muß vemeint werden, daß dieser Aspekt der Ausdehnung der unproduktiven Arbeitssphäre eine, "Verletzung" der Warenform zur Voraussetzung hat. Im Gegen teil, die Veraligemeinerung der Lohnarbeit in alle gesellschaftlichen Arbeitssphären hinein ist geradezu eine "Erfüllung" der Warenform menschlicher Arbeitskraft, denn

aike Zitate a. a. O., S. 46-48 
dieser Prozek impliziert -- wie wir bereits sahen - die Entaltung der Antagonisnen von Lohnabeit und Kapital auch in diesen gesellschaftlichen Bereichen: zunehmende Auspressung von Mehrarbeit, tendenzielle Reduktion kommerzieller und dienstleistender Arbeiten auf einfache Durchschnittsarbeiten, zunenmende Gleichgultig. keit gegenuber dem Arbeitsinhalt und A rbeitsresultat (53) etc., alle derar konstitwerten "Kommkte verueutlichen, dafo diese Arbeitssphären zznehmend den Gesetzmäłsigkeiten der Warenform menschlicher Arbeitskraft unterworfen weden, dath die Antagonismen von Lohnarbeit und Kapitel -- keineswegs auf die produktiven Bereiche beschränkt - die Verhaltnisse in allen Winkeln und und fcken der bügerlichen Gesellschaft, zum Tanzen bringen ": Die Herausbildung der modemen Mitrelklassen bedeutet keineswegs eine verschwindende Bedeutung des Antagonismus von Lohnarbeit und Kapital, wie die politische Krisentheorie glauben machen will.

\section{Ernest Mardel}

In Gegensatz zu Offe versucht Emest Mandel die Herausbilüurg unproduktiver Mittelklassen auf der Grundlage kapitalistischer Akkumulation zu begrelen. Dennoch spricht er wie Offe - wenn auch in anderen Kategorien - von einer, ,fir den Spatkapitalismus kennzeichnenden Expansion des Dienstleistungssektors ${ }^{\circ}(54)$. Nach einer mehr deskriptiven Aufzählung ,konstitutiver Elemente" dieses Expansionsprozesses resumiert er:

„Dic für den Spätkapitalismus spezifische Expansion des Diensileisiungsseklom bidut somit cine tatsächliche Zusammenfassung sämtlicher Haptwiderspruche der kapitalistschen Produktionswise. Sie spiegelt die gewaltige Expansion der geselschaftlich-techischer und wissonschafticher Produktivkäfte und die ihr gematken kulturelien und zivilisatorischen Bedurfniss der Produzenten genauso wie die antagonistische form wider, in der sich diese Expansion im Kapitalismus verwirklicht: begleitet von wachsender Überkapitalisicrung (Verwertungsschwic. rigkeiten): von verschärften Realisierungsschwierigkeiten; von zunehmenker Vergeudung mate. reller Werte; von wachsendet Entfrendung und Verkipplung der Mensehen swoht in inrer produktiven Tätigkeit wie in ihrer Konsumsphäre" (55).

Die voranschreitende Expansion unproduktiver Klassen und Sektoren dient bei Mandel zur Unterscheidung der spätkapitalistischen Phase von vorhergehenden Phasen der herschenden Prodiktionsweise, die Ausdehnung dieser Klassen könne die spezifischen Reproduktionsbedingungen des Spätkapitalismus zum Ausdruck bringen.

Dies muk auf Grund der bisherigen Ausfuhrungen bestritten werden. $A$ wh wenn die vielfaltigen Erscheinungsformen unproduktiver Konsumtions- und Arbeitsprozesse markante Wandlungen erfuhren, denken wir an die verschwindende Bedeutung der ,dienenden Klassen“, an Realisationsarbeiten neuen Typs, an das 53) Siche dazu Projekt Klassenanalyse: Materialion..., a. a. O., \$. 263-305 zum Begriff der Gleichgiltigkeit.

54) E. Mandel: Der Spätkapitalismus, a. a. O., S. 366

5.5) ders.: a. a. $0,5.367$; von mir hervorgehoben 
gewandelte Bild und die gewandelte Zusammensetzung der ideologischen Klassen, an neuartige Dienstleistungssektoren ,Freizeitgestaltung'; soziale ,Fürsorge'arbeiten etc.), an die zunehmende Subsumtion unproduktiver Arbeiten unter die verallgemeinerte Form der Lohnarbeit etc., so bleibt dieser gesellschaftlichen Sphäre trotz der partiellen bis umfassenden Unwälzungen ihres jeweils realen historischen Bildes allgemein, dał ihre Expansion die kapitalistische Produktionsweise insgesamt charakterisiert, die ökonomischen Prozesse, die dieser Expansion zugrundeliegen, keinesfails allein zur Kennzeichnung einer späten Phase dieser Produktionsweise isoliert werden können, auch wenn sich die Stufenleiter dieser Expansion im Fortschreiten kapitalistischer $A$ kkumulation als immer umfassender zrweist.

Welche Momente des Akkumulationsprozesses hat Mandel im Auge, wenn er die Expansion unproduktiver Sektoren zum Kennzeichen spätkapitalistischer Entwicklung erklärt? Dies sind in wesentlichen zwei Aspekte, die sich auch in anderen Zusammenhängen durch seine Arbeit hindurchziehen:

„Letzten Findes entsprechen alle diese Tendenzen der Grundeigensehaft des Spätkapitalismus: der durch die säkular fallende Profitrate alsgelösten und den Übergang zum Monopolkapitalismus beschleunigenden Lischeinung der Uberkapitalisierung der nicht investierbaren Surpluskapitalien"

Zum anderen die ,erhohten Realisierungsschwierigkeiten im Spatkapitalismus. Sie sind gleichzeitig ein Beweis für den Verschwendungscharakter dieser Produktionsweise in ihrer niedergehenden Geschichtsphase" (56a).

Ohne in diesem Rahmen auf die akkumulationstheoretischen Thesen Mandels allgemein einzugehen, können wir aufbauend auf der bisherigen Darstellung doch bestreiten, daß̊ die Expansion unproduktiver Sektoren und Klassen die erhöhten Realisierungsschwierigkeiten und die beschleunigten Überkapitalisierungstendenzen als qualitativ spezifische Prozesse des Spätkapitalismus zum Ausdruck bringt oder gar beweisen konnte. Im Gegenteil, die Expansion dieser Klassen fand ihre materiellen Bedingungen immer schon in diesen Momenten des Akkumulationsprozesses und hat ihrer ,erhöhten" oder ,beschleunigten“ Wirksamkeit nicht bedurft.

Kurzum, der deskriptive Charakter der Ausführungen über die Möglichkeiten und Beschränkungen des Wachstums umproduktiver Klassen, ihrer Bewegungen als Reflexe der Realisations- und Verwertungsprozesse des Kapitals, die weitgehende Identifizierung dieser Bewegungen mit ihren heutigen Manifestationsformen (trotz kritischer Anmerkungen bleibt Mandel dem Begriff des ,Dienstleistungssektors“ als einem Begriff der neueren bürgerlichen Ökonomie verhaftet) führen Mandel dahin, diese Expansion als Spezifikum des Spätkapitalismus zu behaupten, erlauben es ihm andererseits nicht, die Notwendigkeit dieser Entwicklung darzustellen:

„Die Erweiterung des Dienstleistungssektors im Spätkapitalismus ist, vom Standpunkt des Gesamtinteresses der Kapitalistenklasse betrachtet, allenfalls das kleinere Übel. Sje ist dem Brachliegen von Surpluskapitalien vorzuziehen, aber sie bleibt ein Übel, insofern sie dic Gesamtmasse des Jer Kapitalistenklasse zufallenden Mehrwerts direkt überhaupt nicht und indirekt nur in bescheidenem Make vergröbert" (57).

56) ders.: a. a. O., S. 354; won mir hervorgehoven

56a) ders.: a. a. O., S. 363; von mir hervorgehoben

57) ders.: a. a. O., S. 371 
In den Kategorien des ,kleineren Übels ${ }^{66}$ ist der notwendigen Ausdehnung unproduktiver Sektoren und Klassen nicht beizukommen.

\section{Projekt Klassenanalyse (58)}

Im Gegensatz zu Autoren wie Offe, Kuczinski oder Mandel erkennt das Projekt Klassenanalyse (PKA), daß die herrschende Produktionsweise immer schon das Wachstum unproduktiver Mittelklassen implizierte und diese Expansion nicht als qualitativ spezifischer Ausdruck spätkapitalistischer oder imperialistischer Reproduktionsbedingungen begriffen werden kann. Die Herausarbeitung der inneren Struktur der sich verallgemeinernden Lohnarbeit und der Rückgriff auf den Marxschen Begriff der classe moyenne bewahren sie vor einer oberflächlichen Fassung des Begriffs der "Lohnarbeiterklasse". Zugleich vermerken sie gegen Interpretationen, wie sie oben bei Offe kritisiert wurde, daß das Wachstum der Mittelklassen keine Tendenz einer ,Entproletarisierung" darstellt (59). Dennoch kann ihrer Rekonstruktion des Mittelklassenbegriffs nicht zugestimmt werden, und dies hat sei. nen zentralen Grund in den methodischen Prämissen ihres klassentheoretischen Ansatzes:

Im Rahmen der maxxistischen Klassenanalyse, ,müssen zunachst die allgemeinen Bestimanungen der Klassen entwickelt sein, wie sie sich aus dem spezifischen Zusammenhang der ökonomischen Formbestimmungen, sozialen Verhältnisse und Bewuls tseinsformen in der kapitalistischen Gesellschaftsformation ergeben. Die Darstellung der Klassen und der ökonomisehen Bedingungen des Klassenkampfes muls von den Existenzbedingungen der Klassen von Lohnarbeitern, Kapitalisten und Grundeigentümern ausgehen, ihren respektiven Einkommensqucllen Arbeitslohn, Profit und Grundrente, also von den verknöcherten und gegeneinander verselbständigten Formen, in denen dje gesellschaftliche Arbeit an der Oberfläche der Gesellschaft erscheint. Der systematische Ausgangspunkt der folgenden Untersuchung ist damit die Analyse der fertigen Gestalt der gesellschaftlichen Verhältnisse, wie sie von Marx in siebten Abschnitt des dritten Bandes des "Kapital" vorgenommen worden ist. Da aber die Formen, worin die Produzenten und Aneigner des Mehrwerts in ihren alltäglichen Aktionen sich zueinander verhalten, nicht nur in ihrem unmittelbaren Zusammenhang entwickelt, sondern in ihrer Vermitteltheit mit der inneren Natur des kapitalistischen Produktionsprozesses dargestellt werden, geht die Gesamtheit der Formbestimmungen des Kapitalverhältnisses als Voraussetzung in die Untersuchung der Klassenbeziehungen ein" (60).

Die richtige Intention ihres Ansatzes, die Klassenstruktur der bürgerlichen Gesellschaft aus dem spezifischen Zusammenhang der ökonomischen Formbestimmungen zu entwickeln, kann von den Autoren des PKA nicht eingelöst we rden, insofern diese Formen abgehoben von den spezifischen Prozessen betrachtet werden, in denen sie allererst als ökonomische Formen wirken und bestimmbar werden, d. h. die unterschiedlichen Formen menschlicher Arbeit erlangen ihre ökonomische Bestimmtheit nirgends anders als im spezifisch-ökonomischen Reproduktionsprozeß der bürgerlichen Gesellschaft: Die Herausbildung der herrschenden Klassenstruktu-

58) Hier wird allein die neuere Schrift: Materialien ..., a. a. O., betrachtet.

59) dieselb.: a. a. O., S. 274

60) dieselb.: a. a. O., S. 19; von mir hervorgehoben 
ren wind im Ansarz des PKA von ihrer morenielen Grundlage, dem Akkumulationsprozef des Kapiats, abgehoben. Marxistische Staatstheorien(6) und marxistische Klasentheoren, in tenen dis Entwicklung der Form des burgerlichen Staates und der Form der burgethohen Kassenstruktur losgelost von den mneren Widesprichen whd den historischen Velaufsfomen kapitalistscher Akkmulation und ausgehend "von des tertigen Gestalt der geselischaftichen Veraltnisse" he se m Revenue-Abschnit des "Kapital" dargestelt vermuten, erfolot, verkürzen nowendig die Analyse der Fonkonstitution des Staates und der Klassenstruktur arf den Konstitutionsprozek des verkehten Bewuktseins uber und mittels dieser Fomen. So wird vom PKA die Frage nach der therausbildung der die burgentiche Gesellschafe charak. terisierenden Kassenstruktur wejtgehend auf die Frage nach den in der jeweiligen Fom menschlicher Abeit angelegten, wnterschiedichen Möglichkeiten der Ent wickhng von Klassenbewlifstsein isoliert - eine Frage wiederum, die einzig durch den kinbezug der historischen tintwicklungen und Umwälzungen der industriellen. kommerziellen und unprodukiven Arbeitsprozesse, durch den Eimbeug der Geschichte des realen Klassenkanpfes beantwortet werden kann.

Unter diesen Voraussetzungen kann der Maxsche Begriff der Mittelklassen nicht eingeholt werden: Beispielsweise antworten die Autoren gegen Schmierer, der darauf hinweist, dats de Lohn der kommerziellen Arbeiter, wom Gesamtkapital aus betrachtet, niche als wariobles Kapital vorgeschosen wird":

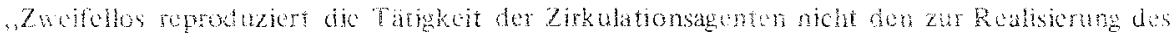

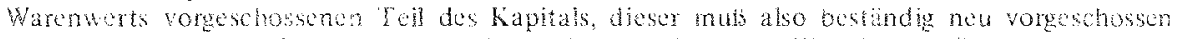

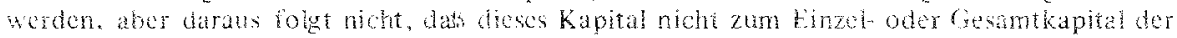

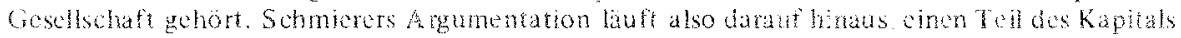
zur kevenue zu erkiren, un die Zirkulatonsagenten des kaptats mit den unproduktiven, aus Revenu beahten Lohnabuternglichusetzen" (62).
}

Nur unter Abstraktion von den Reproduktionsbedingungen, wie sie sich auf der Ebene des Gesantkapitals darstellen, Kann man verkennen, dab der Loh ler kommerzellen Abeitskralte kein Bestandteil des variablen Gesantkapitals $(V)$ ist. Wie irmer sich dieser Tauschprozef vom Standpunkt des einzehnen Kapitals aus darstellt und ohne zu bestreicen, daß kommerzielle Lohnarbeit gegen Kapital und nicht gegen (im engen Sinn:) Revenue tauscht: die Herausbildung der kommerziellen Klasse kann nicht als vermittelter Reflex der Bewegungen des varibien Kapials, sondem muk im Kontext der Bedingungen des Wachstums der unproduktiven Cesantarbeitskraft allgemein begrifen werden. Wie auch bereits in 1 . Teil zu begranden versucht wurde, stellt die Ausdehnung der Sphäe kommerieller Arbeit einen Aspekt des relativen Wachstums der modemen Mitteklassen dar.

Die weitgehende Abstraktion von den widerspruchichen Bewegungen kapitalistischer Akkumulation erlaubt ihnen zum anderen nicht, die Bedingungen des relativen Wachstums der Mittelkiasen zu entwickeln, dioses Wachstum kann so allein, yerzeichnet" werden:

61) Trotz der vorantreibenden Momente ihres Aufsatzes gitt dese Kritik auch S. v. Hatow/F. Huisken: Zum Problon der Ableitung des burgerlichen Stäates, PROKLA 7/1973

62) alle Zitate: PKA: Materialien. ..., a. a. O., S. 484 
,Was ausolute Wachstum der Kapitalistischen Produktion füht zu ennem Wachsen der Zahl der Funktonäre des 砶apitals (das allerdings nicht proportional ist). In ihrer beständigen Expansion begrenzt die kapististische Produktion auch die Existenzmöglichkeiten von Teilen der Mittelkhssen; so $\mathrm{Z} . \mathrm{B}$ der selbständigen Dienstleistungsberufe und der Bedienten. Dennoch ist zugisch ch relatver Rickgang der Zahl der Beschäftigten in Produktions- und Zirkulationsprozen des Kapitals gegenuber den Mittelklasser in ther Gesamtheit zu verzeichnen" (63).

Bort, wo der ingre Votor der Kassengliedenung ausgeblendet wird, bleibt nichts ats on verahnen statistischer Entwicklungen.

Dese wengen Annerkungen mögen genügen, wm zu verdeutlichen, daß der Beginf de: herschenden Kissenstukturen, daß die Rekonstruktion des Marxschen Begriffs der Mitteklassen und die Analyse der Bedingungen ihres Wachstums den Enbezug des kapialistischen Akunulationsprozesses zur unumgänghichen Voraussetanghroun.

63) dieselto: a.a. O., 5. 273

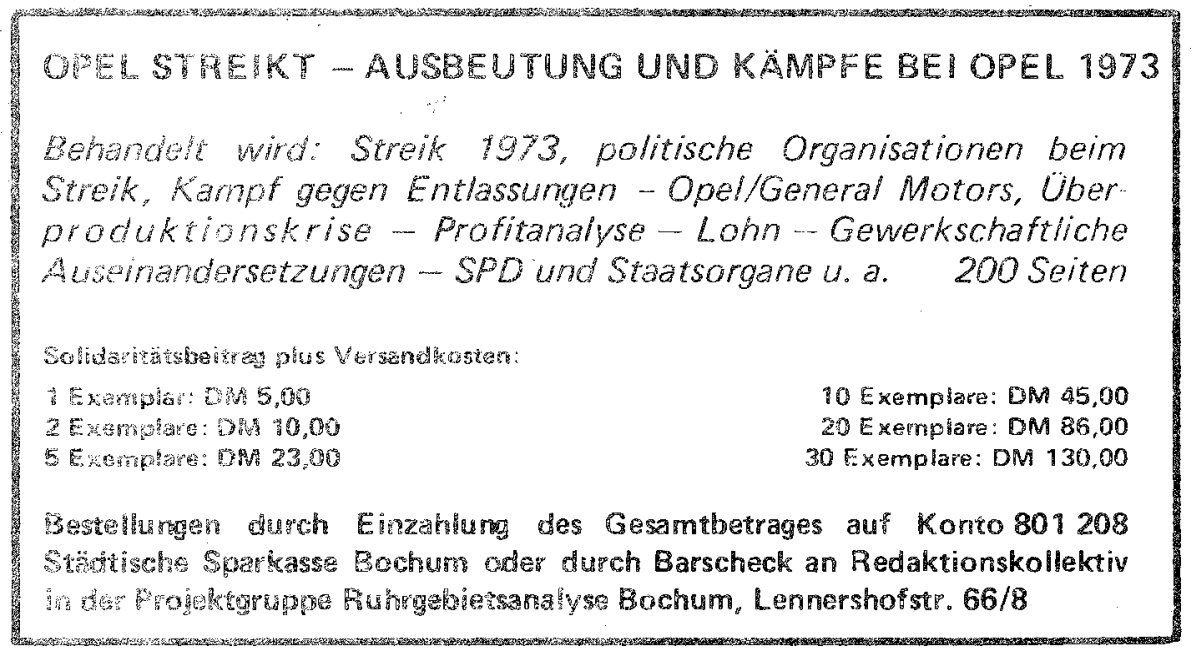

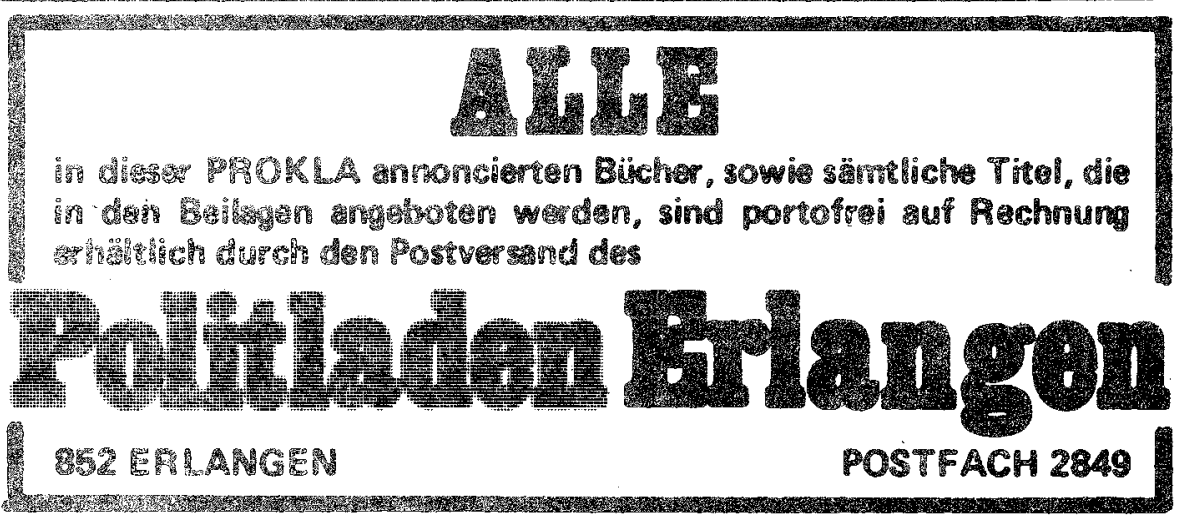

4 Probleme des Klasserample 13 